\section{Lysosomal cell death mechanisms in aging}

Raquel Gómez-Sintes ${ }^{1}$, María Dolores Ledesma ${ }^{2}$ and Patricia Boya ${ }^{1 *}$

${ }^{1}$ Department of Cellular and Molecular Biology, Centro de Investigaciones Biologicas, CIBCSIC. C/ Ramiro de Maeztu 9, 28040 Madrid, Spain.

${ }^{2}$ Department of Molecular Neurobiology, Centro Biologia Molecular Severo Ochoa, CSICUAM, C/ Nicolás Cabrera 1,28049 Madrid, Spain.

\# Corresponding author: Patricia Boya

Department of Cellular and Molecular Biology, Centro de Investigaciones Biológicas, CIBCSIC, C/ Ramiro de Maeztu 9, 28040 Madrid, Spain

Tel.: +34 918373112

Fax: +34 915360432

Email: pboya@cib.csic.e

\section{Keywords}

Lysosomal cell death, cathepsin, lysosomes, lysosomal membrane permeabilization, autophagy, lipids, aging.

Highlights ( $3-5$ bullet points, each max 85 characters including spaces)

- Lysosomal cell death participates in physiological processes, aging, and disease

- Lysosomal membrane permeabilization plays a key role in lysosomal cell death

- Inducers and inhibitors of lysosomal cell death may be of therapeutic value

\section{Abbreviations}

3-MA, 3-methyladenine; 6-OHDA, 6-hydroxydopamine; AD, Alzheimer's disease; AIF, apoptosis inducing factor; ALR, autophagosome-lysosome reformation; ALS, amyotrophic lateral sclerosis; AMD, age-dependent macular degeneration; ApoE, apolipoprotein E; APP, amyloid precursor protein; ASM, acid sphingomyelinase; ATP13A2, ATPase Type 13A2; A $\beta$, $\beta$-amyloid; Baf A, bafilomycin A; BMP, bis(monoacylglycero)phosphate; BPC, biphosphinic palladacycle complex; $\mathrm{CD} 3$, cluster of differentiation 3 receptor; $\mathrm{CMA}$, chaperone-mediated autophagy; Con A, concanamycin A; Cys C, cystatin C; DFO, desferrioxamine; Dp44mT, di-2pyridylketone 4,4-dimethyl-3-thiosemicarbazone; DRAM, damage-regulated autophagy modulator; EGCG, (-)-epigallocatechin-3-gallate; EPM1, progressive myoclonic epilepsy type 1; GCase, glucocerebrosidase; GTSM, thiosemicarbazone; HIV, human immunodeficiency virus; Hsp70, heat shock protein 70; IL-1 $\beta$, interleukin-1 beta; LAP, LC3-associated phagocytosis; LCD, lysosomal cell death; LDL, low-density lipoproteins; Leu-Leu-OMe, Leu-
Leu methyl ester; LMP, lysosomal membrane permeabilization; LPS, lipopolysaccharide; LSDs, lysosomal storage disorders; LysoPC, lysophosphatidylcholine; MEFs, mouse embryo fibroblasts; MMP, mitochondrial membrane permeabilization; MPTP, 1-methyl-4-phenyl1,2,3,6-tetrahydropyridine; MSDH, O-methyl-serine dodecylamide hydrochloride; NAC, Nacetylcystein; PA, phosphatidic acid; PACS-2, phosphofurin acidic cluster sorting protein-2; PD, Parkinson's disease; PLA2, phopholipase A2; PtdIns(3,5)P2, phosphatidylinositol $(3,5)$ biphosphate; rd10, retinal degeneration 10 mice; ROS, reactive oxygen species; RPE, retinal pigment epithelium; siRNA, small interfering RNA; SIRT1, sirtuin 1; SNAREs, soluble $\mathrm{N}$-ethylmaleimide attachment protein receptor proteins; $\mathrm{SOD}, \mathrm{Cu}, \mathrm{Zn}$ superoxide dismutase; TFEB, transcription factor EB; TNF- $\alpha$, tumor necrosis factor $\alpha$; TPEN, NNN'N'-tetrakis (-)(2pyridylmethyl-ethylenediamine; TRAIL, TNF-related apoptosis-inducing ligand; TTMl, tetrathiomolibdate. 
Contents

1. Introduction

2. Types of cell death

2.1 Morphological classification of cell death

2.2 Biochemical and molecular classification of cell death

2.2.2 Lysosomal cell death

2.2.3 Necroptosis

2.2.4 Autophagic and other forms of cell death

3. Lysosomal cell death

3.1 Lysosomes

3.2 Lysosomal membrane permeabilization and the "suicide bag" hypothesis

3.3 Lysosomal cell death: definition and examples

3.4 Inducers of lysosomal cell death

3.5 Downstream consequences of lysosomal cell death

3.6 Inhibitors of lysosomal cell death

3.6.1 Cystatins

3.6.2 Serpins

3.6.3 Hsp70

3.6.4 Cathepsin inhibitors

3.6.5 Antioxidants

3.6.6 Ion chelators

4. Age-associated lysosomal alterations: effects on lysosomal cell death

4.1 Diminished lysosomal function with age: effects on LMP

4.2 Age-associated alterations in lysosomal lipid composition

5. Lysosomal cell death during aging and in aging-related conditions

6. Conclusions

\section{Abstract}

Lysosomes are degradative organelles essential for cell homeostasis that regulate a variety of processes, from calcium signaling and nutrient responses to autophagic degradation of intracellular components. Lysosomal cell death is mediated by the lethal effects of cathepsins, which are released into the cytoplasm following lysosomal damage. This process of lysosomal membrane permeabilization and cathepsin release is observed in several physiopathological conditions and plays a role in tissue remodeling, the immune response to intracellular pathogens and neurodegenerative diseases. Many evidences indicate that aging strongly influences lysosomal activity by altering the physical and chemical properties of these organelles, rendering them more sensitive to stress. In this review we focus on how aging alters lysosomal function and increases cell sensitivity to lysosomal membrane permeabilization and lysosomal cell death, both in physiological conditions and age-related pathologies.

\section{Introduction}

Lysosomal cell death (LCD) is a cell death pathway characterized by lysosomal destabilization followed by the translocation of cathepsins from the lysosomal lumen to the cytoplasm, triggering a cascade of events that culminate in cell death. This form of regulated cell death can be blocked by either pharmacological or genetic inhibition of cathepsin activity (Aits and Jaattela, 2013; Boya and Kroemer, 2008; Serrano-Puebla and Boya, 2015). LCD is observed in several physiological and pathological conditions, and has been recently harnessed as a means of killing cancer cells (Groth-Pedersen and Jaattela, 2013; Petersen et al., 2013). LCD is much less frequent than other forms of cell death, such as apoptosis, and the upstream molecular mechanism remains largely unknown. However, lysosomal membrane permeabilization (LMP) that results in protease release is a key feature of LCD. The downstream consequences of cathepsin release include substrate degradation, caspase activation, and mitochondrial membrane permeabilization (MMP), all of which can be arrested by blocking either LMP or cathepsin activity.

During the normal aging process lysosomes undergo various modifications that diminish their degradative capacity and increase their susceptibility to destabilization. In this review we describe new evidence of LCD regulation and discuss the age-associated decay in lysosomal function. We also examine how age-associated changes in lysosomes, including physical, biochemical, and compositional alterations, may render these organelles more vulnerable to stress and destabilization. Finally, we present evidence of LCD in a variety of physiological and pathological conditions associated with aging.

\section{Types of cell death}

\subsection{Morphological classification of cell deat}

Tissue and organism homeostasis is largely sustained by cell decisions that trigger proliferation, differentiation, and death. Cell death often occurs during development and it has been defined as programmed because occurs at precise developmental stages, in specific cell types, and in a stereotyped manner. Initial studies of this process focused on embryonic and perinatal development, and for many years the definition of cell death was based on morphological criteria. Historically, developmental cell death has been classified into three types, based on morphological criteria and how lysosomes could participate in cell demise (Clarke, 1990; Schweichel and Merker, 1973).

Type I cell death or apoptosis was characterized at the ultrastructural level by shrinkage and fragmentation of the cell (including the nucleus) into small bodies, which are subsequently engulfed by neighboring cells and degraded within the lysosomes of the engulfing cell. This type of cell death is by far the most common and is observed in many tissues under 
physiological and pathological conditions (Clarke, 1990; Kerr et al., 1972). Autophagic or type II cell death was characterized by the formation of autophagic vacuoles, now known as autophagosomes in the dying cells. These are double-membrane vesicles that engulf the cytoplasmic components of the cell, including entire organelles, and are the main hallmark of the self degradation pathway known as autophagy (Kroemer, 2015). Interestingly, this form of cell death was observed in regions in which extensive tissue remodeling occurred. It was postulated that the increased activity of endolysosomes reflected their active participation in the degradation of intracellular components (Schweichel and Merker, 1973). Lastly, necrosis or type III cell death was used to describe cell death with no apparent lysosomal involvement: the main features used to identify this form were the disintegration of cellular structures, plasma membrane fragmentation, and mitochondrial swelling (Schweichel and Merker, 1973).

Over the years, research has highlighted the difficulties in classifying specific cell death subroutines based on the features of dying cells, as similar cell death morphotypes can result from distinct initiation cascades. Furthermore, other factors such as cell type or even cell death kinetics can influence the traits observed during cell death. These difficulties frequently led to misinterpretation (Galluzzi et al., 2012; Kroemer and Levine, 2008), prompting the establishment by the cell death research community of a set of guidelines, based on precise and measurable biochemical features, for the classification of different cell death modalities (Galluzzi et al., 2009). This functional classification of cell death can be easily applied in vitro. However, the study of programmed cell death in whole tissues or organisms remains challenging and mainly relies on the use of gene-deficient transgenic animals and the observation of morphological criteria and their consequences for cell survival.

\subsection{Biochemical and molecular classification of cell death}

In vitro, cell death processes have been assigned to a specific subroutine using complementary biochemical methods that mainly rely on the inhibition of cell death using pharmacological or genetic approaches. According to these criteria apoptosis is usually blocked by caspase inhibitors, necrosis by RIP kinase inhibitors, and LCD by cathepsin inhibitors. A more detailed description of these cell death subroutines is provided below and illustrated in Figure 1.

\subsubsection{Apoptosis}

Apoptosis is usually defined at the biochemical level as caspase-dependent cell death, which can be prevented by general pharmacological caspase inhibition or by overexpression of viral-encoded caspase inhibitors such as $\mathrm{p} 35$. Caspase-dependent apoptosis can be triggered by external cues (extrinsic apoptosis) that activate the so-called death receptors (Figure 1A) Caspases trigger a proteolytic cleavage cascade, ultimately leading to the activation of executor caspases, such as caspase-3. In some instances caspases induce cleavage of the proapoptotic protein Bid, resulting in MMP, which in turn induces the loss of mitochondrial membrane potential, inhibition of the respiratory chain, and translocation of mitochondrial proteins to the cytoplasm. These mitochondrial proteins include cytochrome $\mathrm{c}$, which is released into the cytoplasm and triggers the formation of the apoptosome, a macromolecular complex that activates caspase-3 (Figure 1A). In addition to extracellular signals, damage caused inside the cell can promote apoptotic cell death (intrinsic apoptosis). Most of these processes converge at the mitochondrial level, promoting apoptosome assembly or caspase-independent cell death. One example of the latter is cell death mediated by the mitochondrial protein AIF (apoptosis inducing factor), which induces DNA fragmentation and cell death (Norberg et al., 2010) (Figure 1A). Apoptosis is observed under many physiological settings from development to aging and disease states from cancer, autoimmunity to neurodegeneration.

\subsubsection{Lysosomal cell death}

Cell death induced by the LCD pathway is mediated by ectopic cathepsin activity in response to lysosome destabilization (Figure 1B). The permeabilization of lysosomal membranes facilitates the translocation of cathepsins to the cytoplasm, where they trigger a cascade of deleterious events that culminate in cell death (Aits and Jaattela, 2013; Boya and Kroemer, 2008; Brunk and Ericsson, 1972). This cell death pathway is further described below.

\subsubsection{Necroptosi}

Necroptosis is a recent term that describes the process previously known as regulated necrosis (Galluzzi et al., 2012). While necrosis was long considered an uncontrolled form of cell death it is now clear that this process constitutes a bona fide regulated cell death pathway, which can be blocked by RIP kinase inhibitors (Newton, 2015). RIP kinase is activated in many circumstances including death receptor and toll-like receptor ligation (Figure 1C). Necroptosis has been observed in pathological conditions including infections, stroke, and neurodegenerative and inflammatory diseases (Jouan-Lanhouet et al., 2014).

\subsubsection{Autophagic and other forms of cell death}

Autophagic cell death can be defined at the biochemical level as cell death that can be blocked by genetic or pharmacologic inhibition of autophagy. Less common than apoptosis, programmed autophagic cell death has been observed in vivo in invertebrates: autophagydeficient flies show marked delays in the elimination of several organs during metamorphosis (Zhang and Baehrecke, 2015). However, whether cell death by autophagy occurs in vivo in vertebrates is currently unknown. In vitro, downregulation of autophagy genes has been shown to block cancer cell death in several conditions (Fulda and Kogel, 2015). It is important to note that autophagic cell death is distinct from LCD. Although both are executed by lysosomal 
activity (i.e. proteases) the former would also be blocked by inhibitors of the initiation phase of autophagy (such as 3-MA) or siRNA of autophagy genes.

Other less frequent forms of cell death include anoikis, which occurs when adherent cells lose contact with the matrix (Galluzzi et al., 2012), and mitotic catastrophe (also known as mitotic cell death), in which cells die during mitosis after an aberrant cell cycle or as a consequence of microtubule poisoning (Domenech et al., 2015). Pyroptosis is another form of regulated cell death characterized by caspase 1 activation and was initially observed as an antimicrobial response during inflammation. On detection of intracellular danger signals the cell activates caspase 1 after the formation of multiprotein complexes such as the inflammasome. Activation of the inflammasome results in the maturation and release of IL-1 $\beta$ and other cytokines and in many cases leading to cell death (Galluzzi et al., 2012).

\section{Lysosomal cell death}

\subsection{Lysosomes}

Lysosomes are cytoplasmic membrane-enclosed organelles that degrade macromolecules and cell components. To execute this function these organelles contain a variety of hydrolytic enzymes, including proteases, lipases, nucleases, glycosidases, phospholipases, phosphatases, and sulfatases, which usually achieve maximal enzymatic activity at low $\mathrm{pH}$. The acidic milieu of lysosomes $(\mathrm{pH} \leq 5)$ is maintained by a vacuolar ATPase, which pumps protons from the cytoplasm into the lysosomal lumen (Mindell, 2012). The lysosomal membrane is a single lipid bilayer protected from acidic hydrolases by the expression of specific membrane proteins such as LAMP-1 and LAMP-2; these heavily glycosylated proteins resist digestion and form a protective glycocalyx. Other lysosomal membrane proteins include receptors and proteins that mediate the transport of substances from the lysosomal lumen to the cytoplasm (Settembre et al., 2013; Wartosch et al., 2015) Lysosomes are found in all eukaryotic cell types, except for erythrocytes. However, not all lysosomes are alike. Some have acquired specific functions in certain cell types such as melanosomes and lytic granules, which contain modified lysosomes also known as lysosomerelated organelles (Saftig and Klumperman, 2009). The main functions of lysosomes are listed in Box 1.

Lysosomes are the cell's main catabolic organelle, and several degradation pathways converge at the level of these organelles. The degradation by the lysosome of extracellular material captured by endocytosis and phagocytosis, including plasma membrane receptors, extracellular matrix proteins, phagocytosed bacteria, and apoptotic cells, is known as heterophagy (Figure 2). If the degraded material is derived from the cell itself, the process of lysosome-dependent degradation is deemed to be autophagy (Shen and Mizushima, 2014). Three main autophagic processes have been described to date: macroautophagy, microautophagy, and chaperone-mediated autophagy (CMA) (Figure 2). CMA mediates the transport and degradation of specific cytoplasmic proteins that harbor a specific peptide sequence. Microautophagy and macroautophagy deliver cellular constituents to the lysosome/vacuole, including large protein complexes or aggregates, organelles, invading pathogens such as viruses and bacteria, as well as some short-lived proteins previously thought to be degraded by the proteasome system (Fuster et al., 2010; Perez-Sala et al., 2009; Shen and Mizushima, 2014) (Figure 2)

Lysosome biosynthesis involves the coordinated transcription of genes that encode lysosomal proteins and are regulated by the transcription factor TFEB (Sardiello et al., 2009; Wartosch et al., 2015). Lysosomes can also be recycled from autolysosomes during the end stages of autophagy through autophagosome-lysosome reformation (ALR) (Yu et al., 2010). This process ensures the maintenance of a pool of lysosomes during periods of prolonged starvation that is then rapidly consumed after autophagosome-lysosome fusion. ALR begins with the formation from the lysosome of a tubular structure containing lysosomal membrane proteins such as LAMPs; this structure lacks degradative capacity and has a non-acidic $\mathrm{pH}$ (Chen and $\mathrm{Yu}, 2013$ ).

Other functions of the lysosome include its fusion with the plasma membrane after membrane damage and during wound healing, and release of the lysosomal contents into the extracellular space via a process called lysosomal exocytosis (Box 1). The latter has been observed during bone erosion, tissue remodeling, metastasis and immune cell function (Andrews et al., 2014; Settembre and Ballabio, 2014)

In addition, lysosomes have been recently placed as a central coordinator in the responses to nutrient availability and calcium signaling (Box 1). Lysosomal membranes provide a physical platform for the localization of mTOR, the main sensor and master controller of cell and organism growth. In nutrient rich conditions a macromolecular complex, which blocks autophagy and phosphorylates the transcription factor TFEB is formed on the lysosomal surface. In starvation conditions mTOR translocates to the cytoplasm and no longer phosphorylates TFEB, allowing its translocation to the nucleus, where it binds to the promoter of many essential genes implicated in autophagy and lysosomal biogenesis (Boya, 2012; Settembre et al., 2013). Lysosomes also regulate TFEB via a calcium calcineurin-signaling pathway (Medina et al., 2015). The fine regulation of intralysosomal calcium levels underscores the essential role of the lysosome as a calcium store. The best known calcium channel in the lysosomal membrane is mucolipin 1 (also called TRPML1). This channel releases calcium from the lumen and regulates many aspects of lysosomal function, including trafficking, fusion with 
other organelles, lysosomal reformation, and exocytosis (Xu and Ren, 2015). Interestingly, a recent study found that starvation induces a marked increase in the activity of TRPML1, leading to lysosomal calcium efflux, which facilitates lysosomal reformation (Wang et al., 2015). A new lysosome-to-nucleus signaling pathway that promotes longevity has been recently identified in C. elegans. Lysosomes release lipid messengers that travel to the nucleus, activating nuclear hormone receptors and increasing the longevity of the organism (Folick et al., 2015). Worms fed with this lipid intermediate show an increase in life span. This pathway may also exist in mammals, providing a new perspective on lysosomal control of several essential cell signaling pathways. Last, lysosomes take an active part in cell death processes under physiological and pathological conditions as it is described below.

\subsection{Lysosomal membrane permeabilization and the "suicide bag" hypothesis}

Soon after the discovery of lysosomes, Christian de Duve formulated the "suicide bag hypothesis", which proposed that cell destruction and subsequent death was mediated by the release of lysosomal hydrolases into the cytoplasm after lysosomal membrane destabilization (de Duve, 1959). While this hypothesis was questioned for some time, even by de Duve himself (Clarke, 1990; de Duve, 1975), it is clear now that lysosomal cell death is induced in both physiological and pathological conditions. This regulated form of cell death can be blocked by pharmacological and genetic inhibition of cathepsin activity (Aits and Jaattela, 2013; Boya and Kroemer, 2008). The main feature of LCD is the selective and partial destabilization of the lysosomal membrane, a process known as lysosomal membrane permeabilization, which allows translocation of the lysosomal contents to the cytoplasm (Boya, 2012) (Figure 1B).

Despite growing interest in the mechanism by which lysosomal permeabilization causes cell death, the study and modulation of this phenomenon is still challenging for several reasons. First, lysosomes are heterogeneous organelles and their varying sensitivity to damaging agents means that not all lysosomes within a given cell are simultaneously permeabilized. Second, some caspase inhibitors, particularly at high concentrations, can also block cathepsins, resulting in misclassification of LCD as caspase-dependent apoptosis in some circumstances (Foghsgaard et al., 2001). Third, lysosomal permeabilization does not result in concrete morphological alterations that can be identified by electron microscopy (Brunk and Ericsson, 1972). Finally, some of the more powerful tools used to study LMP have only been recently developed that will for sure facilitate the discovery of new conditions associated to lysosomal-dependent cell death in the near future (Aits et al., 2015).

\subsection{Lysosomal cell death: definition and examples}

We define LCD as a cell demise pathway that results in the permeabilization of lysosomal membranes leading to the translocation to the cytoplasm of cathepsins, which act as executors of cell death. Indeed, pharmacological or genetic inhibition of cathepsin activity protects against LCD. It is clear that massive release of the intraluminal contents of lysosomes triggers uncontrolled cell death, due in part to cytoplasmic acidification and to the degradative activity of lysosomal enzymes (Terman et al., 2006). However, partial and selective LMP has been shown to promote a cascade of events that result in controlled cell death, which can be blocked by cathepsin inhibitors, including cysteine and serine protease inhibitors, which primarily target cathepsin $\mathrm{B}$ and $\mathrm{D}$. Interestingly, these two proteases are also active at neutral $\mathrm{pH}$, supporting the idea of partial and selective LMP, without generalized cytoplasmic acidification (Aits and Jaattela, 2013; Boya and Kroemer, 2008). Thus in LCD cathepsins are considered as the main executors of cell demise. However under some circumstances other cell death pathways are engaged down stream of LMP. For example mitochondrial membrane permeabilization and/or caspase activation has been often observed after LMP and cathepsin release (see below). However and as it has been extensively demonstrated the different cell death subroutines are neither isolated nor mutually exclusive signaling cascades. Depending on the context a particular cell death subroutine can manifest biochemical features of other cell death types as stressors can engage multiple cell lethal mechanisms that show some degree of overlap.

This type of cell death can be considered programmed as it has been observed in vivo in both physiological and pathological settings, including mammary gland involution after lactation, neutrophil aging, and bacterial infection (Aits and Jaattela, 2013; Serrano-Puebla and Boya, 2015). During mammay gland involution, gland cells are eliminated by controlled cell death after weaning. In the first phase of post-lactation regression, lysosomes are permeabilized and release cathepsin B and L into the cell cytoplasm, triggering a wave of caspase-independent cell death. Cathepsin mRNA expression peaks before LMP, a phenomenon dependent on the transcription factor Stat3 (Kreuzaler et al., 2011). Interestingly, Stat3 also regulates the switch in mammary gland cells from a secretory to a phagocytic phenotype and the engulfment of milk fat globules destabilizes lysosomal membranes, leading to cathepsin leakage and subsequent LCD (Sargeant et al., 2014). Thus that LMP-induced cell death contributes to tissue remodeling in physiological conditions.

Neutrophils are important components of the immune system that play key roles in inflammatory responses to a broad spectrum of pathogens. These terminally differentiated cells have a limited life span, ranging from $8 \mathrm{~h}$ to 5 days are the first line of defense of the innate immune system and exert regulatory functions of adaptive immunity during infectious diseases (Mantovani et al., 2011). A recent study demonstrated that spontaneous neutrophil death is mediated by LMP and cytoplasmic release of the serine protease PR3, which promotes the cleavage and activation of caspase 3 and subsequent LCD (Loison et al., 2014b). Inhibition of LMP with the iron chelator DFO or by overexpression of Hsp70 prevents LMP, PR3 
translocation, and cell death. Interestingly PR3-deficient mice show greater numbers of neutrophils in peritoneal exudates after intraperitoneal injection of $E$. coli, indicating reduced neutrophil cell death in vivo, and deletion of the endogenous inhibitor serpin accelerates spontaneous neutrophil death, indicating that LCD operates during in vivo neutrophil homeostasis (Loison et al., 2014b). Interestingly, intracellular bacteria can subvert this pathway to their own benefit: pyocyanin, a toxic metabolite of Pseudonomas Aeruginosa, can induce LMP, cathepsin translocation to the cytoplasm, and LCD of neutrophils, thus favoring bacterial persistence by accelerating neutrophil depletion (Prince et al., 2008). Brucella abortus, a pathogen that evades the innate immune response, has also been recently shown to cause cell death and neutropenia. The molecular mechanism underlying neutrophil cell death remains elusive, but appears to be independent of caspase activation, necroptosis, and pyroptosis, and dependent on the interaction of non-endotoxic LPS with CD14, NADP oxidase, and low amounts of ROS (Barquero-Calvo et al., 2015). However, direct link between LMP and neutrophil death remains to be definitively demonstrated. Interestingly low doses of endotoxic LPS have been shown to alter lysosomal function, including acidification and fusion in primary macrophages (Baker et al., 2015).

LCD is beneficial for the organism in several other situations. For example, when Legionella pneumophila infects primary mouse macrophages, the bacterial protein $\mathrm{RpsL}$ induces macrophage release of cathepsin B, leading to macrophage cell death and the termination of productive infection (Zhu et al., 2015). Similarly, macrophages fight pneumococci through LMP, releasing cathepsin D and inducing cell death. Cathepsin inhibition in this system impairs bacterial clearance in the mouse lung (Bewley et al., 2011). Viruses that co-evolve with host cells adapt many cellular functions to their own ends, including LMP-induced cell death. For example, DRAM expression is upregulated in human immunodeficiency virus (HIV)-infected $\mathrm{CD}^{+} \mathrm{T}$ cells, inducing LMP-mediated death of the infected cell and contributing to viral infection (Laforge et al., 2013). LMP-induced cell death is thus a homeostatic response that helps the organism to rid itself of intracellular pathogens and facilitates tissue remodeling. As described below, LCD has also been described in numerous animal models of human diseases such as stroke, Parkinson's disease, and lysosomal storage disorders (LSDs) (see Section 5).

\subsection{Inducers of lysosomal cell death}

There are many situations in which the lysosomal membrane is destabilized, promoting LMP and cathepsin release (Table 1). The first evidence of lysosomal destabilization was reported over 30 years ago when cultured cells were treated with lysosomotropic detergents (Firestone et al., 1979). These compounds have detergent-like properties and an affinity for the acidic environment of the lysosome. They accumulate after protonation and upon reaching a certain concentration destabilize the lysosomal membrane (Firestone et al., 1979). In line with their affinity for the acidic intraluminal milieu of the lysosome, the lethal effects of these agents, several examples of which are provided in Table 1, are blocked by lysosomal basification.

Inducing pore formation in the lysosomal membrane is the simplest way to trigger cathepsin release into the cytoplasm. Several venoms and bacterial toxins have this effect (Boya and Kroemer, 2008). VepA from the bacterium Vibrio cholerae can directly permeabilize isolated lysosomes and induce the release of cathepsin D, causing lysosomal death during infection (Matsuda et al., 2012). Pneumolysin from Streptococcus pneumoniae also has poreforming activity and promotes LMP leading to cathepsin B release and inflammasome activation in differentiated human monocytic cell lines (Bewley et al., 2014). Interestingly, in vivo cathepsin B inhibition is associated with better outcomes and reduced brain inflammation in a murine model of meningitis (Hoegen et al., 2011). Whether this effect is related to increased death of infected cells remains to be determined. Recent findings indicate that in addition to bacterial and viral proteins, endogenous toxin-like molecules such as aerolysin-like proteins are also capable of inducing LMP (Xiang et al., 2014). These molecules can translocate to lysosomes, forming high molecular-mass detergent-stable oligomers that promote lysosomal destabilization and cathepsin B release. Xiang and coworkers reported that this phenomenon is associated with increased interleukin- $1 \beta$ maturation and release and enhanced survival after bacterial infection in mice (Xiang et al., 2014).

Like MMP, LMP has been recently shown to be regulated by members of the Bcl-2 family of proteins. One of these proteins, Bax, translocates to lysosomal membranes after treatment with several inducers such as palmitate and the parkinsonian neurotoxin MPTP (Bove et al., 2014; Feldstein et al., 2006). Bax tranlocation to lysosomal membranes in turn induces LMP and cathepsin-dependent cell death (Bove et al., 2014; Kagedal et al., 2005). DRAM, another p53-responsive gene, induces LCD in HIV-infected cells (Laforge et al., 2013). Interestingly, Bax translocation to lysosomes appears to be mediated by DRAM, at least in some settings (Guan et al., 2015). Bim, another Bcl-2 family member also translocates to lysosomal membranes and induce LMP. This mechanism depends on the phosphofurin acidic cluster sorting protein-2 (PACS-2) a multifunctional sorting protein (Werneburg et al., 2012). Under what circumstances Bcl-2 family members preferentially translocate to lysosomes or mitochondrial membranes to induce their permeabilization and exert their lethal effects remains to be elucidated.

Lysosomes do not possess enzymes such as catalase or glutathione peroxidase, which have the capacity to degrade hydrogen peroxide. Therefore, in response to high levels of oxidative stress, large amounts of hydrogen peroxide diffuse across the lysosomal membrane. 
Lysosomes are enriched in iron, a consequence of the degradation of iron-containing molecules within these organelles. Fe (II) can catalyze the homolytic cleavage of hydrogen peroxide to form hydroxyl radicals (via the Fenton reaction), the most reactive free radicals (Terman et al., 2006). Oxidative stress is thus one of the main causes of LMP and is observed in many scenarios (Table 1). This explains why the age pigment lipofuscin, which consists of oxidized material, usually forms within lysosomes (Terman et al., 2006) (see Section 4 below). In contrast to other organelles, lysosomal membranes contain high levels of the antioxidant vitamin E, which probably protects against high levels of hydroxyl and peroxide radicals.

The loss of mTOR phosphorylation sites on the autophagy regulator UVRAG was recently shown to increase lysosome tubulation and LCD after prolonged starvation (Munson et al., 2015). Interestingly, this sensitizes cells to the effects of lysosomotropic detergents, suggesting that LCD could be a consequence of alterations in lysosomal reformation. Consistently, defects in ALR have been shown to induce neuronal death (Chang et al., 2014; Varga et al., 2015).

Some lipids and lipidic metabolites could trigger LMP. Some of them have detergentlike properties and subsequently act as lysosomotropic agents. This is the case of sphingosine, accumulated in lysosomes as the result of ceramide transformation or sphingosine kinase 1 inhibition (Taha et al., 2005; Ullio et al., 2012). Also arachidonic acid, a lipid metabolite generated by phopholipase A2 (PLA2) produced LCD based on detergent-like properties (Zhang et al., 2006). Moreover, oxidation products of cholesterol, as 7 $\beta$-hydroxycholesterol, are being used as LMP inducing factors in cancer cells (Roussi et al., 2007).

Apart from being LCD effectors cathepsins could act as LMP promoters. This has been demonstrated by using cathepsin B-deficient fibroblast where reduced LMP is observed in cathepsin B-deficient cells after TNF- $\alpha$ treatment (Werneburg et al., 2002). Many other factors induce LMP, including photodamage, nanoparticles and crystals, although the specific underlying mechanisms remain to be elucidated (Table 1). Despite intensive research in the field of lysosomal death over the last decade, the precise mechanism of action of many LMPinducing agents is still unknown. Research in this area will likely be stimulated by recently developed novel investigative techniques, particularly given the potential of these factors in the treatment of cancer (Kirkegaard and Jaattela, 2009).

\subsection{Downstream consequences of lysosomal cell death}

The downstream consequences of LMP and cathepsin translocation depend on many factors, which can be cell autonomous (e.g., the intensity and duration of the stimuli) or intrinsic (e.g., levels of endogenous inhibitors, antioxidant defenses, and immortalization status of the cell) (Fehrenbacher et al., 2004). At the molecular level, one of the consequences of cathepsin release after LMP is cleavage of the protein Bid. This promotes the translocation to the mitochondria of the proapoptotic proteins Bax and Bak which induce mitochondrial membrane permeabilization (MMP) and trigger caspase-dependent cell death. In many instances cathepsin inhibition reduces Bid cleavage, MMP, and cell death. Cathepsin activity induces the degradation of anti-apoptotic proteins such as XIAP and induce caspase-dependent cell death (Taniguchi et al., 2015). Other proteins such as Noxa can modulate LMP-dependent cell death (Eno et al., 2013). In many instances, amplifying loops that propagate lysosomal damage are observed during oxidative stress. In this scenario ROS not only target lysosomal membranes but also damage mitochondrial membranes, further exacerbating the oxidative stress to which lysosomes are subjected. These findings suggest that multiple downstream pathways are activated during LCD (Serrano-Puebla and Boya, 2015)

Cancer cells often combine mutations in pro-apoptotic proteins and overexpression of anti-apoptotic proteins make them resistant programmed apoptotic cell death. Evidence suggests that cell death can still occur through LMP and lysosomotropic agents have been postulated as potential therapies for cancer (Kirkegaard and Jaattela, 2009). In addition cancer cells present modifications in lysosomes, as for example increased size, which makes them more vulnerable to LMP. Thus tumour cells could be be more sensible that non-tranformed cells to the toxic effects of lysosomotropic agents (Groth-Pedersen and Jaattela, 2013). Also approaches as pharmacological or genetic inhibition of endogenous stabilizers of lysosomal membrane, i.e Hsp70, could be successful to kill cancer cells. In this line, levels of Hsp 70 in distinct cancer cells lines, correlate with the response to therapies based on LMP (Mena et al., 2012).

\subsection{Inhibitors of lysosomal cell death}

Inhibitors of LCD are defined as molecules capable of blocking lysosome permeabilization cathepsin activity and the death of the cell (Figure 3). There are many examples that are able to rescue from cell death under many settings. These molecules can be endogenous in origin, and include cystatins, serpins, and Hsp70, which inhibit the action of lysosomal hydrolytic enzymes or stabilize the lysosomal membrane (Nylandsted et al., 2004). The internal glycocalyx of the lysosome also protects the membrane from the acidic $\mathrm{pH}$ of the lysosomal lumen and the action of lysosomal proteases (Settembre et al., 2013). Exogenous inhibitors such as antioxidants and chelators also protect against LMP. The study of LCD inhibitors, both endogenous and exogenous, is now an important area of research given the potential relevance of these compounds in to protect from disease and aging.

\subsubsection{Cystatins}


Cystatins (cysteine protease inhibitors) are proteins that can neutralize lysosomal cysteine proteases such as as cathepsins. Three families of cystatins have been identified: stefins, (type I), cystatins (type II) and kininogens or type III cystatins (Perisic Nanut et al., 2014; Turk and Bode, 1991). Given that their targets, cathepsins, are predominantly localized within lysosomes, it appears that the function of intracellular cystatins is to block the activity of these proteases, when released into the cytoplasm following lysosomal damage (Perisic Nanut et al., 2014; Turk et al., 2001). Cystatin B or stefin B (Stfb) is a cathepsin B inhibitor. Cancer cells in mice lacking Stfb are significantly more sensitive to treatment with the lysosomotropic agent Leu-Leu-OMe, suggesting an in vivo role for Stfb in protecting against cancer cell death (Butinar et al., 2014). Cystatin C (Cys C), also a cathepsin B inhibitor, has been shown to prevent cell death in PC12 cells treated with 6-OHDA (Lee et al., 2006; Lee et al., 2007). In $\mathrm{N} 2 \mathrm{~A}$ cells and in primary rat cortical neurons, Cys $\mathrm{C}$ decreases cell death following serum deprivation, oxidative stress, and treatment with colchicine and staurosporine (Tizon et al., 2010).

Studies in vivo have also demonstrated the utility of cystatins in preventing LMP and cell death. In a mouse model of amyotrophic lateral sclerosis (ALS) carrying the mutant copper/zinc superoxide dismutase (SODI) gene, Cys $\mathrm{C}$ is present in motor neurons and astrocytes, while Cys B is found in activated microglial cells and at reduced levels in motor neurons, suggesting a role in motor neuron neurodegeneration (Wootz et al., 2006). The addition of exogenous Cys $\mathrm{C}$ to motor neurons of SOD1 mice in primary culture protects against cell death (Watanabe et al., 2014). Interestingly, in vitro and in vivo studies have demonstrated induction of autophagy via mTOR suggesting that beneficial effect of cystatin is not purely due to cathepsin inhibition (Tizon et al., 2010; Watanabe et al., 2014). In rat brain, analyses of endogenous cathepsin B and cystatin $\mathrm{C}$ have revealed changes in the expression of both proteins after traumatic brain injury (Martinez-Vargas et al., 2014). Moreover, intracerebroventricular injection of cystatin C prior to trauma exacerbates brain injury at high doses, but attenuates neuronal death at low doses (Martinez-Vargas et al., 2014). Interestingly, when crossed Cys B KO mice, a mouse model of progressive myoclonic epilepsy type 1 (EPM1) by Cys C KO, symptoms as neuronal loss in cerebellum were exacerbated while crossbreeding Cys B KO mice by mice overexpressing Cys C symptoms were reversed (Kaur et al., 2010).

\subsubsection{Serpins}

Serpins (serine protease inhibitors) are protease inhibitors that can exert both extracellular and intracellular effects. Some serpins can inhibit caspases and cathepsins at the intracellular level and block LCD (Law et al., 2006). In C. elegans, SRP6 has prosurvival function in srp6 null individuals by blocking lysosomal lysis produced by hypotonic shock and other insults (Luke et al., 2007). In several cancer cell lines, SCCA1, a homologue of C. elegans SRP-6, prevents lysosomal injury after exposure to DNA alkylating agents and hypotonic shock (Ullman et al., 2011). Interestingly, despite its role in protecting against lysosomal injury, SCCA1 promotes cell death induced by ER stress. Finally, a recent study reported that SERPINB1, a PR3 inhibitor, prevents spontaneous death in aging neutrophils, and described a protective effect of Prtn 3 knockdown in a mouse model of induced peritonitis (Loison et al., 2014a). Neutrophil survival studies in serpin 1B knock-out mice revealed a cytoprotective role for this serpin function based on the inhibition of granule protease cathepsin G (Baumann et al., 2013).

\subsubsection{Hsp70}

Heat shock protein 70, Hsp70, another endogenous protein inhibitor of LMP, is located at the endosomal/lysosomal membrane. This chaperone stabilizes lysosomes by binding to Bis(monoacylglycero)phosphate (BMP), an endosomal anionic phospholipid, and facilitates its binding to acid sphingomyelinase (ASM) reverting the toxic effects of siramesine, a lysosomotropic agent that inhibits ASM leading to lysosomal membrane permeabilization (Nylandsted et al., 2004; Petersen et al., 2013). Depletion of Hsp70 in cancer cells has been shown to trigger LMP and it can be reverted by cystein proteases inhibitors. Interestingly, Hsp70 expression in fibroblasts protects against TNF or etoposide induced lysosomal death (Nylandsted et al., 2004). Moreover, endogenous levels of Hsp70 in different cancer cell lines can be determinant for the resistance to polyphenol induced cathepsin leakage and cell death (Mena et al., 2012; Petersen et al., 2010). In cells from Niemann-Pick disease patients, decreased ASM activity is positively correlated with lysosomal stability, a phentoype that can be corrected with recombinant Hsp70 treatment (Kirkegaard et al., 2010). Thus Hsp70 plays an important role in preserving lysosomal membrane under many circumstances and its inhibition has also been suggested as a promising new strategy to fight cancer.

\subsubsection{Cathepsin inhibitors}

Pharmacological inhibitor of cathepsins as pepstatin A also block LMP in cancer cells following photodamage and resveratrol treatment (Marino et al., 2013; Trincheri et al., 2007). Another cystein protease inhibitor, E64d reduced srp-6 null C. elegans induced LMP (Luke et al., 2007). Both, pepstatin A and E64d, protected against death in neurons of SOD1 mice (Watanabe et al., 2014). Several reports demonstrate that the selective cathepsin B inhibitor CA-074Me is able to reduce LMP and cell death is several in vivo models such as a mouse model of metastatic cancer (Bechara et al., 2014), a mouse model of Kawasaki disease (Chen et 
al., 2015) and during mammary gland involution, where it delays the regression of the gland after weaning (Kreuzaler et al., 2011).

\subsubsection{Antioxidants}

Antioxidants are exogenous agents commonly used to inhibit LMP and cell death, and do so mainly by preventing ROS-induced LMP (Zang et al., 2001). $\alpha$-tocopherol has been shown to protect against caspase-independent apoptosis after sigma-2 ligand-induced LMP in cancer cells (Hornick et al., 2012), and to prevent cell death fibroblasts after LMP induction with siramesine, a sphingomyelinase inhibitor (Petersen et al., 2013). Another widely used antioxidant, $\mathrm{N}$-acetylcystein (NAC), prevents cell death caused by EGCG ((-)-epigallocatechin3-gallate) in different cell types (Zhang et al., 2012). NAC also protects against Dp44mTinduced toxicity (Gutierrez et al., 2014) and both caspase-dependent and caspase-independent cell death induced by sigma-2 ligands (Hornick et al., 2012).

Antioxidants can also protect against photodamage-induced LMP. Trolox, an analog of Vitamin E, and vitamin C block ROS generation in human carcinoma cells treated with the photosensitizer Pc13 (Marino et al., 2013). Another photosensitizer, NPe6, produces ROS in photodynamic conditions, an effect prevented by treatment with vitamin $\mathrm{C}$ and Nac (Liu et al., 2011). In a model of oxygen-glucose deprivation in rat hippocampal slices, both trolox and $\mathrm{N}$ tert-butyl- $\alpha$-phenyl nitrone reduced ROS levels and blocked LMP (Windelborn and Lipton, 2008). Vitamin $C$ also protects against LMP and mitochondrial destabilization induced by $7 \beta-$ hydroxytosterol and 7 $\beta$-hydroxycholesterol (Roussi et al., 2007). Finally, ebselen, another antioxidant and a potent scavenger of hydrogen peroxide and peroxynitrite, protects endothelial cells against cardiovascular stressors, stabilizing the lysosomal membrane by preventing cathepsin-mediated cleavage of SIRT1 (Chen et al., 2012)

\subsubsection{Ion chelators}

Ion homeostasis and membrane potential are both essential for lysosomal function, and modulation of these parameters is one means of preventing LCD. Lysosomal calcium regulates most stages of lysosomal trafficking, including lysosomal fusion to autophagosomes and late endosomes (Xu and Ren, 2015). Recent findings suggest that TFEB-dependent transcriptional regulation of autophagy and lysosomal biogenesis relies on levels of lysosomal $\mathrm{Ca}^{2+}$, which are controlled by the calcium channel TRPML1 (Medina et al., 2015; Xu and Ren, 2015). Calcium chelators have thus emerged as useful tools to protect against LMP-induced damage. Treatment of cancer cells with BPC induces Bax translocation to the mitochondrial membrane and caspase-3 activation, effects that are reversed by the calcium chelator BAPTA-AM (Bechara et al., 2014). Similarly, in the aforementioned C. elegans study (Luke et al., 2007), treatment of srp-6 null animals with EGTA-AM or BAPTA-AM protected against death. Thus calcium chelators are emerging tools to protect against several injuries associated to LMP.

Iron catalyses Fenton reactions inside the lysosome which products are highly reactive pro-oxidants. An imbalance in the respective concentrations of these ions could promote ROS formation, triggering LMP. In line with this view, various metal chelators have been shown to inhibit LMP. The iron chelator desferrioxamine (DFO) can block LMP induced by hydrogen peroxide or by other ROS inducers such as gentamycin and Dp44mT (Castino et al., 2007; Castino et al., 2011; Denamur et al., 2011; Gutierrez et al., 2014). The DFO derivative azitromycin can also block lysosomal leakage after induction of oxidative stress in murine macrophages (Persson et al., 2012). LMP triggered by DNA damage following exposure to ionizing radiation in cancer cells is blocked by the iron chelator SIH (salicylaldehyde isonicotinoyl hydrazone), which also protects lung tissue from damage caused by ionizing radiation in cancer treatment (Berndt et al., 2010).

Lysosomes are also the intracellular stores of other ions such as $\mathrm{Zn}^{2+}$ and $\mathrm{Cu}^{2+}(\mathrm{Xu}$ and Ren, 2015). The zinc chelator TPEN (NNN'N'-tetrakis (-)(2-pyridylmethyl-ethylenediamine) can reverse lysosomal cell death induced by tamoxifen in severall cell types (Cho et al., 2012; Hwang et al., 2010). Furthermore, TPEN decreases ethambutol-induced LMP when simultaneously added with $\mathrm{Zn}^{2+}$ to primary rat retinal cell cultures (Chung et al., 2009). Finally, the copper chelator tetrathiomolibdate (TTMl) inhibits LMP after treatment with thiosemicarbazone (GTSM) (Stefani et al., 2015). Given that ion accumulation may increase ROS formation and hence cell death, chelators constitute a useful means of maintaining ion concentration inside lysosomes, thus preventing cell damage. Selectively directed chelators may also protect specific tissues from the effects of ionizing radiation used in the treatment of cancer (Berndt et al., 2010).

Maintenance of lysosomal pH is essential to ensure proper function of the lysosomal degradation machinery. In this context, V-ATPase plays an important role in acidifying the lysosomal lumen and enabling the enzymatic activity of lysosomal proteins (Florey, 2015). In EGCG-induced LMP in cancer cells and MEFs, chloroquine, a lysosomotropic agent, rescues cell death by blocking LMP-induced cytosolic acidification (Zhang, 2012). Chloroquine induces an osmotic imbalance, increasing $\mathrm{pH}$ and blocking canonical autophagic flux. A recent study also demonstrated that chloroquine (and monensin) can induce LC3-II lipidation via a mechanism resembling LAP (LC3-associated phagocytosis), and that this effect is exacerbated by $\mathrm{NH}_{4} \mathrm{Cl}$ and blocked by the V-ATPase inhibitors Baf A and Con A (Florey et al., 2015).

It is important to mention here a study demonstrating the protective role of DMSO against LMP, mitochondrial damage, and ROS formation induced by 7-OH-cholesterol in U937 
cells (Laskar et al., 2010). Given that DMSO is widely used as a diluent, these particular effects should be taken into account when interpreting results from experiments in which this compound is used.

In conclusions these results support the interest of cathepsins as targets for preventing LMP consequences. Modulation of endogenous proteins, as cystatins, serpins and Hsp70, levels may have some therapeutic potential: on one hand increasing cystatin levels could protect cells in neurodegenerative or age-related conditions, while on the other hand downregulating these proteins could sensitize cancer cells to treatment with LMP inducers, potentially improving therapeutic outcomes.

\section{Age-associated lysosomal alterations: effects on lysosomal cell death}

\subsection{Diminished lysosomal function with age: effects on LMP}

Free radicals are formed as a consequence of normal metabolism and accumulate throughout life, leading to the characteristic accumulation of oxidized proteins, lipids, and DNA in aged tissues. This is particularly evident in postmitotic cells in which cell division prevents the dilution of damaged cell components. It is now clear that aging reduces the overall degradative capacity of cells and is accompanied by a general decline in the activities of the proteasome and the lysosome (Reeg and Grune, 2015). Many factors may be responsible for the reduction in lysosomal activity that accompanies the aging process. As described below, some age-dependent alterations may render lysosomes more sensitive to stress, increasing the likelihood of LMP and subsequent cell death (Figure 4).

Most cells display an age-associated increase in lysosome number and size. This increase in lysosomal volume has also been observed during senescence (Kurz et al., 2000) and is associated with enhanced fragility and increased LMP in response to various stimuli (Ono et al., 2003). Moreover, aged lysosomes exhibit an accumulation of undigested material. This is caused by oxidized macromolecules, which undergo secondary modifications that render them less susceptible to the action of acidic hydrolases within the lysosomes. These posttranslational modifications include lipid peroxidation and protein carbonylation, which promote the formation of highly crosslinked and oxidized material. The best known example is lipofuscin, also known as age pigment, which is used as a marker of aging as is readily detected owing to its autoflourescence. Lipofuscin preferentially accumulates inside lysosomes and its formation is accelerated by Fenton reactions that occur inside these organelles in response to oxidative stress. Evidence supports the view that increased lipofuscin accumulation within the lysosome may alter its degradative function (Brunk and Terman, 2002). Another possibility is that lipofuscin accumulation triggers lysosomal destabilization, a view supported by a recent study reporting the presence of lipofuscin in the cytoplasm, probably as a consequence of LMP (Reeg and Grune, 2015)

Reduced protease activity may also contribute to the decreased degradative capacity of aged tissues. This could be in part due to alterations in lysosomal $\mathrm{pH}$, as described in several in vitro and animal models of age-related pathological conditions such as Alzheimer's disease, macular degeneration, and glaucoma (Guha et al., 2014a; Porter et al., 2015; Wolfe et al., 2013). Increasing lysosomal $\mathrm{pH}$ using lysosomotropic agents (e.g., certain antibiotics) induces LMP and cell death in several cell types (Boya et al., 2003a; Boya et al., 2003b). However, it can be difficult to determine intralysosomal $\mathrm{pH}$ in tissues, and a direct link between altered lysosomal $\mathrm{pH}$ and LCD during aging remains to be confirmed.

An increase in calpain cleavage products has been observed during aging and has been linked not only to increases in calpain levels but also to alterations in the corresponding substrates make them more susceptible to cleavage. In many circumstances calpain lies upstream of cathepsin release during LCD. As such, increases in calpain activity could render aged cells more susceptible to LMP. Calpain has been shown to cleave many substrates that can increase lysosomal death by inducing LMP (e.g., LAMP-2) (Villalpando Rodriguez and Torriglia, 2013). A similar sequence of calpain activation, cathepsin release, and subsequent cell death is observed in several pathological conditions explained in section 5 .

The aforementioned findings support the view that the effects of aging on lysosomal function are the result of a decreased degradative capacity together with increased production of damaging agents. Together, these alterations sustain an amplificatory loop that further exacerbates the phenotype (Figure 4). Compared with younger tissue, lysosomes in aged tissues are larger and more fragile, which appears to make these organelles more susceptible to LMP, thus increasing the likelihood of tissue malfunction as a consequence of LCD.

\subsection{Age-associated alterations in lysosomal lipid composition}

Lysosomes are membrane organelles. As such, changes in the levels of lipids, which are the most abundant membrane components, are likely to influence lysosomal function. While the contribution of specific lipids to lysosomal physiology is poorly characterized, a growing body of evidence points to a key role in lysosomal integrity, fusion, and protein stability. Lipids may influence these processes not only by determining the physical properties of membranes but also by regulating the lateral mobility, clustering, and stability of lysosomal proteins. Several studies have highlighted the effects of lipids on lysosomal proteins. For example cholesterol levels regulate the assembly and recycling of soluble $\mathrm{N}$-ethylmaleimide attachment protein receptor proteins (SNAREs). These transmembrane proteins assemble in complexes between two opposing membranes to drive the fusion process (Jahn and Scheller, 2006). Proper function 
of lysosomal SNAREs depends on dynamic interactions, regulated by SNARE compartmentalization at the lysosomal membrane in cholesterol-enriched microdomains (socalled rafts). Changes in cholesterol content alter the dynamics of SNARE interactions, impairing lysosomal fusion with other membranes (Fraldi et al., 2010). Indeed, decreases in cholesterol diminish the efficiency of lysosomal fusion with autophagosomes in in vitro fusion assays (Koga et al., 2010). Dynamic compartmentalization at the lysosomal membrane is also crucial for the function of the LAMP-2A receptor, which mediates CMA (Kaushik et al., 2006) (Figure 2). LAMP-2A binds to cytosolic substrates and mediates their translocation to the lysosomal lumen for degradation (Bandyopadhyay et al., 2008). The organization of LAMP-2A into multimeric complexes required for substrate translocation only occurs outside cholesterolenriched lipid microdomains; LAMP-2A located within these domains is susceptible to proteolytic cleavage and degradation (Kaushik et al., 2006). In agreement with this observation, decreases in lysosomal cholesterol levels result in the displacement of LAMP-2A from lipid rafts, increasing CMA activity, while cholesterol loading leads to LAMP-2A degradation and impairment of CMA (Kaushik et al., 2006). The mucolipin (TRPML1), the main lysosomal calcium channel, is another lysosomal protein modulated by lipids. Although the underlying molecular mechanisms are unclear, TRPML1 activity is inhibited by high sphingomyelin levels, but potentiated by sphingomyelinases (Shen et al., 2012). Accordingly, lysosomes in acid sphingomyelinase-deficient cells from Niemann Pick type A disease patients show reduced calcium release and sphingomyelin accumulation.

Lipids also play a role in maintaining lysosomal integrity by protecting against membrane permeabilization. As stated above the chaperone Hsp70 contributes to lysosomal stabilization by binding to the endolysosomal anionic phospholipid BMP, a co-factor essential for sphingomyelin metabolism in lysosomes (Kirkegaard et al., 2010). This interaction enhances the activity of the enzyme acid sphingomyelinase, which mediates sphingomyelin catabolism. In line with this observation, acid sphingomyelinase deficiency leads to lysosomal membrane permeabilization and subsequent cytosolic release of cathepsins (Gabande-Rodriguez et al., 2014).

Given the central role of lipids in lysosomal physiology, a key question is whether lysosomal lipid composition changes with age. Research has only recently begun to address this question. Comparison of liver lysosomes from mice of 3 and 22 months of age has revealed significant lipid changes in older mice, including increased levels of cholesterol, ceramide, glucosylceramide, and lysophosphatidylcholine (Rodriguez-Navarro et al., 2012). Overall, aging promotes changes in acyl chain composition, thus increasing the levels of sphingomyelin, ceramide, and glucosylceramide unsaturated in both chains, as well as the percentage of saturated phosphatidylcholine. Short saturated sphingomyelin species are also abundant in older lysosomes (Figure 4). Interestingly, many of the age-related lipid changes seen in lysosomes resemble those observed after dietary lipid challenge (e.g., chronic exposure to a high-fat diet or acute exposure to cholesterol-enriched diet) (Rodriguez-Navarro et al., 2012).

The aforementioned findings support the view that lipid changes contribute to the decay of lysosomal function that accompanies aging (Figure 4). However, whether these changes occur in tissues other than the liver and the specific consequences in the context of aging remain unknown. Several hypotheses have been put forward based on current knowledge of the roles of lipids in lysosomal function in health and disease. It has been proposed that increased levels of cholesterol and short saturated forms of sphingomyelin may give rise to more rigid lipid raft microdomains (Rodriguez-Navarro et al., 2012). This may underlie the age-dependent decline in CMA (Kiffin et al., 2007) caused by decreased lysosomal levels of LAMP-2A. Previous analyses have ruled out changes in rates of LAMP-2A synthesis or trafficking to lysosomes in older organisms, and have demonstrated that LAMP-2A half-life is reduced due to accelerated degradation of this receptor protein (Rodriguez-Navarro et al., 2012). The reported increases in cholesterol and sphingomyelin in aged lysosomes may enhance the incorporation of LAMP-2 into rafts, and hence its subsequent degradation (Kaushik et al., 2006). Increased levels of these lipids could also promote the sequestration of lysosomal SNAREs in lipid rafts, impairing SNARE fusion function (Fraldi et al., 2010). High levels of cholesterol and sphingomyelin may alter autophagosomal clearance by affecting the activity of lysosomal proteases (Elrick et al., 2012) or by promoting their release into the cytoplasm due to lysosomal membrane permeabilization, as described in Niemann Pick disease type $\mathrm{C}$ and A cells (Gabande-Rodriguez et al., 2014). The accumulation of ceramide in lysosomes has also been associated with altered lysosomal enzyme activity and destabilization, as demonstrated in cells depleted of the ceramide export protein LAPTM4B (Blom et al., 2015). While the increase in cholesterol, sphingomyelin, and ceramide levels observed in aged lysosomes is moderate (5-15\%), lysophosphatidylcholine (LysoPC) levels are markedly increased (45\%) (Rodriguez-Navarro et al., 2012). It is thus important to note the reported ability of LysoPC to increase lysosomal permeability to potassium ions and protons, an effect that enhances the osmotic sensitivity of these organelles (Hu et al., 2007). This phenomenon could make older lysosomes more liable to destabilization in response to osmotic shock and less efficient in controlling their $\mathrm{pH}$. Indeed, a recent study in yeast identified lysosomal pH as a critical regulator of aging (Hughes and Gottschling, 2012). The authors reported that vacuolar $\mathrm{pH}$ in yeast decreases with age. Given the highly conserved functions of the vacuole throughout evolution, it has been postulated that similar alterations may occur in eukaryotic lysosomes.

Taken together these data support the view that changes in the physical and biochemical features of lysosomes contribute to the age-associated functional decay of these organelles. A 
better understanding of these changes and their consequences in different tissues, as well as the underlying causes and molecular mechanisms, will be crucial to design strategies to combat LCD mechanisms triggered by aging.

\section{Lysosomal cell death during and in aging-related conditions}

Age-related changes with age in lysosomal system have been extensively studied in liver, where proteolytic pathways were more characterized. In this organ, morphological changes described above as enlarged lysosomal compartments, accumulation of autophagic vacuoles and lipofuscin deposition, occur during aging (Brunk and Terman, 2002; Terman, 1995; Vittorini et al., 1999). In rodents, a decreased in macroautophagic activity in liver seems to be consequence of both accumulation of autophagic vacuoles and hormone regulation of this type of autophagy. Also, in lysosomes isolated from livers of old rats, CMA has been found to be decreased correlating with a decrease in LAMP2A levels (Cuervo and Dice, 2000). Selective knock-in mice for LAMP-2A in liver, accumulate less damaged proteins, improve cellular homeostasis and improve liver function, thus indicating that maintenance of autophagic and lysosomal systems slows down age related organ failure (Zhang and Cuervo, 2008). In skeletal muscle, there is a progressive loss of muscle mass due to an imbalance of synthesis/degradation of proteins during aging. A muscle specific Atg7 knock-out mouse model, presents muscle atrophy and age dependent decrease in force that is enhanced after fasting or denervation (Masiero et al., 2009).

Another tissue showing high vulnerability to lysosomal defects with age is the brain. As an example, imbalance on cathepsin activities has been detected during aging process of neurons, contributing to neurodegeneration (Nakanishi, 2003). More precisely, levels of cathepsin $\mathrm{D}$ are increased and show extralysosomal localization in brains from old rats (Jung et al., 1999; Lynch and Bi, 2003). Also, a more subtle increase in cathepsin B and $\mathrm{E}$ activities have been found with age whereas a decrease in cathepsin L is observed (Nakanishi et al., 1994. Moreover, these changes in cathepsin levels and localization are common to neurons and glial cells in the brain and are restricted to areas in the brain with increased vulnerability to agerelated diseases. Another hallmark of aging lysosomes, lipofuscin, accumulates in old rat neurons \{Oenzil, 1994 \#8492). In normal human aged brain, Atg5, Atg7 and beclin1 genes are down-regulated indicating a defective autophagy (Lipinski et al., 2010). In studies in mouse retina, there is a decrease in macroautophagy (reduced mRNA expression of Beclin1 and Atg7 as well as altered autophagic flux), accompanied by an increase in lipofuscin, ubiquitin and p62 with age (Rodriguez-Muela et al., 2013).
Lysosomal alterations and LCD have been identified as key pathological events in diseases that develop with age, particularly neurodegenerative diseases (Serrano-Puebla and Boya, 2015). The aberrant accumulation of proteins is a common feature of many of these diseases. Strategies that enhance lysosomal clearance or enhance lysosomal biogenesis are thus emerging as potential therapies (Nixon, 2013).

Atheriosclerosis is a major cause of cardiovascular disease in aged individuals. This chronic inflammatory process is characterized by the accumulation of modified low-density lipoproteins (LDL) in the arteries. These lipidic accumulations induce endothelial dysfunction and macrophage activation. Increased oxidative stress promotes the oxidation of LDLs to forms that induce LMP and cell death (Roussi et al., 2007). A recent study reported that increased expression of the transcription factor TFEB restores lysosomal function in macrophages and attenuates the deleterious effects of lipid accumulation during atherogenesis. Taken together, these findings suggest that lysosomal function is markedly impaired in atherosclerosis and that the induction of a lysosomal biogenesis program in macrophages has antiatherogenic effects (Emanuel et al., 2014).

Severe lysosomal neuropathology has been described in animal models of Alzheimer's disease (AD), the most common age-dependent neurodegenerative disorder, and in the brains of AD patients (Nixon and Yang, 2011). Different mechanisms have been proposed to explain this phenotype, which is associated with the accumulation of $\mathrm{A} \beta$ peptides, a key hallmark of AD. A recent study proposed that the deposition of extracellular $\beta$-amyloid around axons may alter retrograde axonal transport, and found that in several mouse models of $\mathrm{AD}$ this effect was correlated with the accumulation of altered lysosomes containing reduced levels of multiple soluble luminal proteases (Gowrishankar et al., 2015). Decreased levels of Hsp70 and increased levels of cathepsin D, LAMP-1, and ubiquitinated proteins are found in neurally-derived exosomes taken from AD patients prior to the onset of clinical signs (Goetzl et al., 2015). Furthermore, alterations in mTOR signaling and reduced autophagy in postmortem tissue from $\mathrm{AD}$ patients correlate with decreased expression of the autophagy regulator Beclin1 (Antonell et al., 2015; Tramutola et al., 2015). Collectively, these observations indicate alterations occurring at multiple levels within the endolysosomal system in $\mathrm{AD}$ patients.

Early onset $\mathrm{AD}$ can be caused by presenilin 1 mutations, which alter lysosomal proteolysis and autophagy (Lee et al., 2010), leading to calcium dyshomeostasis due to impaired V-ATPase-mediated lysosomal acidification (Lee et al., 2015). Increases in calcium levels, calpain activation, and LCD are observed in many models of neuronal cell death including excitotoxicity and stroke (Yamashima and Oikawa, 2009). In these settings calpains participate in cell death by cleaving several proteins that confer lysosomal stability, including Hsp70 (Serrano-Puebla and Boya, 2015). It has been proposed that similar mechanisms 
underlie LCD in AD (Yamashima, 2013). In addition, recent evidence suggests that defective macroautophagic turnover of brain lipids may be responsible for the deleterious effects observed in a mouse model of AD (Yang et al., 2014). Indeed, levels of various lipid species, including cholesterol and ceramide, are elevated in autophagic vacuoles and lysosomes in neurons of mice overexpressing mutant human amyloid precursor protein (APP). Stimulation of lysosomal cathepsins ameliorates lipid accumulation within these organelles (Yang et al., 2014). Increased levels of several cathepsins, some of which show $\beta$-secretase activity in APP processing, have also been observed around senile plaques (Pislar et al., 2014). Interestingly, extracellular accumulations of cathepsins $\mathrm{B}, \mathrm{L}$, and $\mathrm{D}$ associated with $\mathrm{A} \beta$ deposits have been described in the brains of patients with $\mathrm{AD}$, but not in other neurodegenerative diseases such as Parkinson's or Huntington's disease (Cataldo and Nixon, 1990). The same authors reported that hydrolase immunoreactivity in senile plaques is associated with lipofuscin granules in membrane-limiting structures, suggesting that they could be lysosomes released from neurons or that could remain in the tissue after neuronal death (Cataldo et al., 1991). The fact that this is a non-selective process, involving the release of the entire contents of the lysosome, also suggests that lysosomal membrane permeabilization could be involved (Cataldo et al., 1991). Moreover, $\mathrm{A} \beta 1-42$, the more toxic and aggregate-prone species, accumulates in the lysosomes of $\mathrm{AD}$ neurons, leading to lysosomal leakage and the release of enzymes into the cytoplasm, both of which correlate with morphological evidence of cellular toxicity (Yang et al., 1998).

Interestingly, ApoE4, the strongest genetic risk factor for late onset $\mathrm{AD}$, is a lipid transport protein with the ability to destabilize lysosomal membranes (Ji et al., 2002). It has been proposed that, in response to the presence of amyloid peptide, ApoE4 forms a reactive molecular intermediate that binds phospholipids and becomes embedded within the lysosomal membrane, destabilizing it and causing lysosomal leakage and apoptosis (Ji et al., 2002). In summary, these findings describe multiple lysosomal alterations, including decreased stability and increased LCD, in AD disease models. Furthermore, alterations observed in $\mathrm{AD}$ patients support the view that LCD plays a pathogenic role in this disease.

Pathological and genetic findings point to alterations in the autophagic lysosomal pathway and LCD in Parkinson's disease (PD), another major age-related neurodegenerative disorder (Isacson, 2015). Decreased levels of lysosomal membrane proteins together with translocation of lysosomal proteases to the cytoplasm and LCD have been reported in MPTPtreated mice, a classical model of PD (Dehay et al., 2010; Vila et al., 2011). Proper lysosomal function is essential to avoid the accumulation of $\alpha$-synuclein, which is degraded within the lysosome via a process dependent on cathepsins B, L as well as by cathepsin D (McGlinchey and Lee, 2015; Qiao et al., 2008; Sevlever et al., 2008). Lysosomal lipid imbalance has also been implicated in the lysosomal pathology characteristic of PD. Mutations in the genes encoding for the lysosomal glucocerebrosidase (GCase), which degrades the lipid glucosylceramide, are among the most common genetic risk factors for PD (Mazzulli et al., 2011). Inhibition of the glucocerebrosidase (GCase) decreases pH-dependent autophagy and lysosomal degradation of $\alpha$-synuclein (Mazzulli et al., 2011). Moreover, GCase enzymatic activity is decreased in the brains of patients with sporadic PD, leading to glucosylsphingosine accumulation (Rocha et al., 2015), while glucocerebrosidase gene therapy prevents $\alpha$ synucleinopathy of midbrain dopamine neurons (Rocha et al., 2015). Given that GCase deficiency is also observed in healthy aged individuals, it has been proposed that the aging of lysosomal systems occurs more rapidly in individuals at risk for PD. A recent study described a lipid switch that unlocks the activity of the lysosomal P-type transport ATPase ATP13A2, whose activity is impaired in PD. ATP13A2 activity is stimulated by its interaction with lysosomal signaling lipids such as phosphatidic acid and phosphatidylinositol $(3,5)$ biphosphate PIP $(3,5)$, thus protecting against $\alpha$-synuclein toxicity and mitochondrial stress in cellular models of PD. These findings support a pathological link between lipid alterations and lysosomal dysfunction in PD and suggest that lysosomal enhancement may be a useful therapeutic strategy (Holemans et al., 2015). Further supporting this putative therapeutic role, the transcription factor $L m x 1 b$, which influences the expression of the overall regulator gene for lysosomal biogenesis (TFEB) in dopaminergic neurons of the midbrain, is necessary to prevent degeneration of these neurons (Laguna et al., 2015). A similar cytoprotective effect is observed when TFEB is overexpressed in cellular model of MPP+ toxicity (Dehay et al., 2010)

LCD has been observed in several retinal diseases including retinitis pigmentosa, a neurodegenerative condition that results in blindness caused by caspase-independent photoreceptor cell death (Sancho-Pelluz et al., 2008). A recent report described the pro-survival effect of cathepsin B and calpain inhibitors in retinal degeneration 10 (rd10) mice, which mimic the disease (Rodriguez-Muela et al., 2015). Because photoreceptor cells in these mice show LMP and enhanced cathepsin B activity, LCD has been proposed as one of the mechanisms underlying photoreceptor loss in inherited retinal degeneration (Rodriguez-Muela et al., 2015). Calpain activation has been linked to LMP and cell death in a mouse model of light-induced retinal degeneration (Villalpando Rodriguez and Torriglia, 2013). Interestingly, this condition is characterized by the degradation of LAMP-2, suggesting that lysosomal labilization may be a consequence of altered membrane stability. Chloroquine has been used for many years for the treatment of malaria and autoimmune diseases such as lupus. Chloroquine and its derivatives (e.g., hydroxychloroquine) become trapped inside the lysosome, increasing the $\mathrm{pH}$ of the organelle and, in cases of prolonged treatment, causing lysosomal cell death (Boya et al., 2003b). One of the main side effects of chloroquine is retinal toxicity, which is caused by alterations in retinal pigment epithelial (RPE) function and leads to photoreceptor dysfunction 
(Mahon et al., 2004). RPE cells are essential to maintain retinal homeostasis and control the phagocytosis of shed photoreceptor outer segments, a process by which essential components are degraded and recycled to sustain the visual cycle. Alterations in RPE cells are associated with age-dependent macular degeneration (AMD), a major cause of blindness and visual impairment in older adults. While no direct in vivo evidence of lysosomal membrane permeabilization in RPE cells has been reported, altered lysosomal function has been observed with age. These alterations in lysosomal function include intralysosomal accumulation of undigested A2E, a subproduct of the visual cycle that reduces the degradative capacity of RPE cells (Finnemann et al., 2002). Another age-associated change in the RPE is an increase in lysosomal mTOR levels, an alteration shown to decrease the rate of degradation of photoreceptor outer segments (Subrizi et al., 2015). Moreover, in the human ARPE-19 cell line, destabilization of the lysosomal membrane with lysosomotropic detergents induces LMP, inflammasome activation, and cell death (Tseng et al., 2013). Whether lysosomal death contributes to human macular degeneration remains to be elucidated.

Glaucoma is another age-associated retinal disease. This condition results in the death of retinal ganglion cells, which connect the eye to the brain, ultimately causing blindness. The complete molecular mechanism underlying glaucoma is yet to be fully unraveled, but damage to the optic nerve by for example increases in intraocular pressure has been associated to elevated risk of glaucoma. Dysfunction of the trabecular meshwork cells, such as that caused by ageassociated oxidative stress, also increases intraocular pressure (Liton, 2016). Interestingly, lysosomal damage and cathepsin D release are observed in these cells in conditions of oxidative stress. Importantly, the iron chelator DFO protects against cell death (Lin et al., 2010), suggesting that lysosomal death of trabecular meshwork cells also contributes to the aging phenotype of glaucoma (Liton et al., 2009). Novel therapies that target lysosomes may be developed for the treatment of certain retinal diseases; potential approaches include the use of recombinant Hsp70 (Subrizi et al., 2015) or agents that increase intralysosomal pH (Guha et al., 2014b).

Amyotrophic lateral sclerosis (ALS) is a neurodegenerative disease characterized by rapid motor neuron degeneration leading to muscle atrophy and paralysis (Bruijn et al., 2004). The SOD1G93A transgenic mouse, a widely used model of ALS, carries a human mutant $\mathrm{Cu} / \mathrm{Zn}$ superoxide dismutase (SOD) transgene. The G93A mutation is present in about $20 \%$ of patients with familial ALS (fALS), and SOD1G93A mice develop motor neuron degeneration similar to that seen in fALS patients (Gurney et al., 1994). These mice also display alterations in the expression and distribution of cathepsins B, L, and D, as well as cystatins B and C (Wootz, 2006). Cysteine $C$ is present in the Bunina bodies of spinal motor neurons in sporadic ALS patients (Okamoto et al., 1993) and is decreased in the cerebrospinal fluid of ALS patients
(Tsuji-Akimoto et al., 2009). Moreover, Cys C protects primary cultured neurons from toxicity induced by mutations in SOD1. This neuroprotective action depends on both cathepsin B inhibition and the induction of autophagy (Watanabe et al., 2014). In both ALS patients and SOD1 mice mRNA levels of cathepsin B and cathepsin D are consistently increased. Moreover, increases in cathepsin B are observed in 90 day-old SOD1 mice, suggesting a possible role of cathepsin B in the early stages of the disease (Offen et al., 2009). In ALS patients, cathepsin B is primarily found in shrunken and pigmented neurons, a pattern that differs considerably to that seen in healthy control cases. By contrast, the distribution of cathepsins $\mathrm{D}, \mathrm{H}$, and L is similar in both groups (Kikuchi et al., 2003). Immunohistochemistry analysis in ALS patients shows a diffuse distribution of cathepsin $\mathrm{B}$ and $\mathrm{D}$ in in the cytoplasm rather than aggregated in lysosomes. This may indicate the release of cathepsin B due to lysosomal membrane permeabilization, although further analyses will be required to verify this hypothesis.

\section{Conclusions}

Cell death mechanisms play crucial roles both in tissue homeostasis and disease. A growing body of evidence points to LCD as an important pathway in cell demise. Although less common than other cell death mechanisms, LCD has been implicated in cell death in physiological settings (e.g., mammary gland involution), and its participation in a variety of pathological conditions, including infection, cancer, and neurodegenerative diseases, has stimulated research in this field. While the molecular mechanisms underlying LCD are not fully understood lysosomal permeabilization appears to play a central role. These events have been linked to the functional decline of lysosomes observed during physiological aging. Identifying the specific mechanisms involved in LCD, as well as inducers and inhibitors of this process, are important steps to better understanding the cellular effects of aging and disease. Novel technologies will help to achieve this goal, ultimately creating new avenues for the development of therapeutic strategies for several human diseases.

\section{Acknowledgments}

We thank Ana Serrano-Puebla (CIB-CSIC) and Edgardo Moreno (Universidad Nacional, Costa Rica) for helpful comments and discussion, Mateo Casas-Engel for artwork, and Owen Howard for English editing. Work in our laboratories is supported by grants from MINECO Consolider CSD2010-00045 to PB and MDL, SAF2012-36079 to PB and SAF201457539-R to MDL. We apologize to those authors whose work could not be included due to limits on the article's length. 


\section{Figure legends}

Figure 1. Cell death pathways. (A) Apoptosis: cell death by apoptosis can be triggered by extrinsic signals that act on death receptors and activate caspases. Death receptors and intrinsic signals also activate proapoptotic members of the Bcl-2 family, such as Bid, which induce mitochondrial membrane permeabilization (MMP), cytochrome $\mathrm{c}$ release, and apoptosome assembly, ultimately triggering caspase-dependent cell death. Apoptosis is blocked by caspase inhibitors. (B) Lysosomal cell death is triggered by lysosomal membrane permeabilization (LMP), which results in the translocation of cathepsins to the cytoplasm and subsequent cell death. LMP can also be induced by oxidative stress (reactive oxygen species; ROS) and can generate an amplification loop, further exacerbating both LMP and MMP. Lysosomal cell death can be blocked by cathepsin inhibitors, antioxidants, and chelators and by endogenous molecules such as cystatins and serpins. (C) Necroptosis is a cell death pathway that results in the activation of the RIP kinase family of proteins. Necrostatin and other RIP kinase inhibitors protect against cell death. In several circumstances the aforementioned pathways are interconnected.

Figure 2. Pathways that converge on lysosomes. Heterophagy delivers to the lysosomes material for degradation such as as bacteria, and apotptic cells. Autophagy is classified into several forms. Macroautophagy is characterized by the formation of an intermediate organelle, the autophagosome, which entraps cytoplasmic components, including entire organelles. The engulfed material is degraded upon fusion of the autophagosome with the lysosome. In chaperone-mediated autophagy proteins bearing the KFERQ motif are specifically delivered to the lysosome via interactions with chaperone proteins, such as Hsp70. This molecule in turn interacts with LAMP-2A, a receptor on the lysosomal membrane, triggering the unfolding and translocation of the protein inside the lysosomal lumen. Finally, microautophagy involves the direct transportation into the lysosome of molecules selected for degradation.

Figure 3. Endogenous and exogenous inhibitors of lysosomal cell death. LAMPs and LIMPs are highly glycosylated proteins that form a glycocalyx, a covering which protects proteins and lipids from the effects of hydrolases stored within the lysosome. Expression of Hsp70 also protects lysosomal membranes from oxidative damage and other LMP triggers. Following their release into the cytosol, the activity of cathepsins can be blocked by endogenous cathepsin inhibitors such as cystatins and serpins. Antioxidants, chelators, and cathepsin inhibitors are the main exogenous inhibitors of lysosomal cell death.

Figure 4. Age-associated lysosomal alterations. The figure reflects changes observed in aged lysosomes compared to those in non-aged (mature). Among them are lipofuscin accumulation and increased size, $\mathrm{pH}$ and levels of certain lipids such as cholesterol, short saturated sphingomyelin and lysosphosphatidylcholine. These lipid changes may result in more rigid raft domains, which reduce the dynamic compartmentalization of SNAREs and LAMP-2. This could impair SNARE function and enhance LAMP-2 degradation. Sphingomyelin increase may also reduce the activity of the lysosomal calcium channel TRPML1. On the other hand, high levels of lysophosphatidylcholine could increase the permeability of the lysosomal membrane. Together these modifications in the membrane probably render old lysosomes more vulnerable to oxidative damage and permeabilization, leading to lysosomal cell death. 


\section{References}

Aits, S., Jaattela, M., 2013. Lysosomal cell death at a glance. J Cell Sci 126, 1905-1912.

Aits, S., Kricker, J., Liu, B., Ellegaard, A.M., Hamalisto, S., Tvingsholm, S., Corcelle-Termeau, E., Hogh, S., Farkas, T., Jonassen, A.H., Gromova, I., Mortensen, M., Jaattela, M., 2015. Sensitive detection of lysosomal membrane permeabilization by lysosomal galectin puncta assay. Autophagy 11, 1408-1424.

Andrews, N.W., Almeida, P.E., Corrotte, M., 2014. Damage control: cellular mechanisms of plasma membrane repair. Trends Cell Biol 24, 734-742.

Antonell, A., Llado, A., Sanchez-Valle, R., Sanfeliu, C., Casserras, T., Rami, L., Munoz-Garcia, C., Dangla-Valls, A., Balasa, M., Boya, P., Kalko, S.G., Molinuevo, J.L., 2015. Altered Blood Gene Expression of Tumor-Related Genes (PRKCB, BECN1, and CDKN2A) in Alzheimer's Disease. Mol Neurobiol.

Baker, B., Geng, S., Chen, K., Diao, N., Yuan, R., Xu, X., Dougherty, S., Stephenson, C., Xiong, H., Chu, H.W., Li, L., 2015. Alteration of lysosome fusion and low-grade inflammation mediated by super-low-dose endotoxin. J Biol Chem 290, 6670-6678.

Bandyopadhyay, U., Kaushik, S., Varticovski, L., Cuervo, A.M., 2008. The chaperone-mediated autophagy receptor organizes in dynamic protein complexes at the lysosomal membran. Mol Cell Biol 28, 5747-5763.

Barquero-Calvo, E., Mora-Cartin, R., Arce-Gorvel, V., de Diego, J.L., Chacon-Diaz, C., ( Bre

Action of Its Lipopolysaccharide. PLoS Pathog 11, e1004853.
Baumann, M., Pham, C.T., Benarafa, C., 2013. SerpinB1 is critical for neutrophil survival through cell-autonomous inhibition of cathepsin G. Blood 121, 3900-3907, S3901-

Bechara, A., Barbosa, C.M., Paredes-Gamero, E.J., Garcia, D.M., Silva, L.S., Matsuo, A.L., Nascimento, F.D., Rodrigues, E.G., Caires, A.C., Smaill, S.S, B.S., Mel, 2014 Palladacycle (BPC) antitumour activity against resistant and metastatic cell lines: the relationship with cytosolic calcium mobilisation and cathepsin B activity. Eur J Med Chem 79, 24-33.

Berndt, C., Kurz, T., Selenius, M., Fernandes, A.P., Edgren, M.R., Brunk, U.T., 2010. Chelation of lysosomal iron protects against ionizing radiation. Biochem J 432, 295-301.

Bewley, M.A., Marriott, H.M., Tulone, C., Francis, S.E., Mitchell, T.J., Read, R.C., Chain, B., Kroemer, G., Whyte, M.K., Dockrell, D.H., 2011. A cardinal role for cathepsin d in coordinating the host-mediated apoptosis of macrophages and killing of pneumococci. PLoS Pathog 7, e1001262.

Bewley, M.A., Naughton, M., Preston, J., Mitchell, A., Holmes, A., Marriott, H.M., Read, R.C., Mitchell, T.J., Whyte, M.K., Dockrell, D.H., 2014. Pneumolysin activates macrophage lysosomal membrane permeabilization and executes apoptosis by distinct mechanisms

without membrane pore formation. MBio 5, e01710-01714.
Blom, T., Li, S., Dichlberger, A., Back, N., Kim, Y.A., Loizides-Mangold, U., Riezman, H., Bittman, R., Ikonen, E., 2015. LAPTM4B facilitates late endosomal ceramide export to control cell death pathways. Nat Chem Biol 11, 799-806.

Bove, J., Martinez-Vicente, M., Dehay, B., Perier, C., Recasens, A., Bombrun, A., Antonsson, B., Vila, M., 2014. BAX channel activity mediates lysosomal disruption linked to

Boya, P., 2012. Lysosomal Function and Dysfunction: Mechanism and Disease. Antioxid Redox Signal 17, 766-774

Boya, P., Andreau, K., Poncet, D., Zamzami, N., Perfettini, J.L., Metivier, D., Ojcius, D.M., Jaattela, M., Kroemer, G., 2003a. Lysosomal membrane permeabilization induces cell ondrion-dependent fashion. J Exp Med 197, 1323-1334.

Boya, P., Gonzalez-Polo, R.A., Poncet, D., Andreau, K., Vieira, H.L., Roumier, T., Perfettini, L., Kroemer, G., 2003b. Mitochondrial membrane permeabilization is a critical step of lysosome-initiated apoptosis induced by hydroxychloroquine. Oncogene 22, 3927-3936.
Boya, P., Kroemer, G., 2008. Lysosomal membrane permeabilization in cell death. Oncogene $27,6434-6451$

Bruijn, L.I., Miller, T.M., Cleveland, D.W., 2004. Unraveling the mechanisms involved in motor neuron degeneration in ALS. Annu Rev Neurosci 27, 723-749.

Brunk, U.T., Ericsson, J.L., 1972. Cytochemical evidence for the leakage of acid phosphatase through ultrastructurally intact lysosomal membranes. Histochem J 4, 479-491.

Brunk, U.T., Terman, A., 2002. Lipofuscin: Mechanisms of age-related accumulation and influence on cell function. Free Radical Biology and Medicine 33, 611-619.

Butinar, M., Prebanda, M.T., Rajkovic, J., Jeric, B., Stoka, V., Peters, C., Reinheckel, T., Kruger, A., Turk, V., Turk, B., Vasiljeva, O., 2014. Stefin B deficiency reduces tumor growth via sensitization of tumor cells to oxidative stress in a breast cancer model. Oncogene 33, 3392-3400

Castino, R., Bellio, N., Nicotra, G., Follo, C., Trincheri, N.F., Isidoro, C., 2007. Cathepsin DBax death pathway in oxidative stressed neuroblastoma cells. Free Radic Biol Med 42, 1305-1316

Castino, R., Fiorentino, I., Cagnin, M., Giovia, A., Isidoro, C., 2011. Chelation of lysosomal iron protects dopaminergic SH-SY5Y neuroblastoma cells from hydrogen peroxide toxicity by precluding autophagy and Akt dephosphorylation. Toxicol Sci 123, 523541.

Cataldo, A.M., Nixon, R.A., 1990. Enzymatically active lysosomal proteases are associate

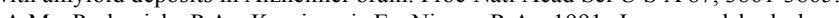
different classes are abnormally distributed in brains of patients with Alzheimer disease. Proc Natl Acad Sci U S A 88, 10998-11002.

Chang, J., Lee, S., Blackstone, C., 2014. Spastic paraplegia proteins spastizin and spatacsin mediate autophagic lysosome reformation. J Clin Invest 124, 5249-5262.

Chen, J., Xavier, S., Moskowitz-Kassai, E., Chen, R., Lu, C.Y., Sanduski, K., Spes, A., Turk, B., Goligorsky, M. S, 2012. Cathepsin cleavage of sirtuin 1 in endothelial progenitor cells mediates stress-induced premature senescence. Am J Pathol 180, 973-983.

Chen, Y., Li, X., Boini, K.M., Pitzer, A.L., Gulbins, E., Zhang, Y., Li, P.L., 2015. Endothelial Nlrp3 inflammasome activation associated with lysosomal destabilization during coronary arteritis. Biochim Biophys Acta 1853, 396-408.

Chen, Y., Yu, L., 2013. Autophagic lysosome reformation. Exp Cell Res 319, 142-146.

Cho, K.S., Yoon, Y.H., Choi, J.A., Lee, S.J., Koh, J.Y., 2012. Induction of autophagy and cell death by tamoxifen in cultured retinal pigment epithelial and photoreceptor cells. Invest Ophthalmol Vis Sci 53, 5344-5353.

Chung, H., Yoon, Y.H., Hwang, J.J., Cho, K.S., Koh, J.Y., Kim, J.G., 2009. Ethambutolinduced toxicity is mediated by zinc and lysosomal membrane permeabilization in cultured retinal cells. Toxicol Appl Phannacol 235, 163-170.

Clarke, P.G., 1990. Developmental cell death: morphological diversity and multiple mechanisms. Anat. Embryol. (Berl) 181, 195-213.

Cuervo, A.M., Dice, J.F., 2000. Age-related decline in chaperone-mediated autophagy. J Biol Chem 275, 31505-31513

de Duve, C., 1959. Lysosomes, a new group of cytoplasmic particles, in Subcellular Particles (T. Hayashi, editor). New York, Ronald Press Co.

de Duve, C., 1975. Exploning cells with a contifuge. Science 189, 186-194.

Dehay, B., Bove, J., Rodriguez-Muela, N., Perier, C., Recasens, A., Boya, P., Vila, M., 2010.

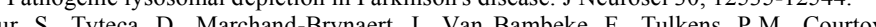

Denamur, S., Tyteca, D., Marcer., P.J., Mingeot-Leclercq, M.P., 2011. Role of oxidative stess in lysosonal membrane Free Radic Biol Med 51,1656-1665.

Domenech, E., Maestre, C., Esteban-Martinez, L., Partida, D., Pascual, R., Fernandez-Miranda, G., Seco, E., Campos-Olivas, R., Perez, M., Megias, D., Allen, K., Lopez, M., Saha, A.K. Velasco, G., Rial, E. Mendez, R., Boya, P., Salazar-Roa, M., Malumbres, M. 
2015. AMPK and PFKFB3 mediate glycolysis and survival in response to mitophagy during mitotic arrest. Nat Cell Biol 17, 1304-1316. Elrick, M.J., Yu, T., Chung, C., Lieberman, A.P., 2012. Impaired proteolysis underlies
autophagic dysfunction in Niemann-Pick type C disease. Hum Mol Genet 21, 48764887

Emanuel, R., Sergin, I., Bhattacharya, S., Turner, J.N., Epelman, S., Settembre, C., Diwan, A., Ballabio, A., Razani, B., 2014. Induction of lysosomal biogenesis in atherosclerotic macrophages can rescue lipid-induced lysosomal dysfunction and downstream sequelae. Arterioscler Thromb Vasc Biol 34, 1942-1952.

Eno, C.O., Zhao, G., Venkatanarayan, A., Wang, B., Flores, E.R., Li, C., 2013. Noxa couples lysosomal membrane permeabilization and apoptosis during oxidative stress. Free Radic Biol Med 65, 26-37

Fehrenbacher, N., Gyrd-Hansen, M., Poulsen, B., Felbor, U., Kallunki, T., Boes, M., Weber, E., Leist, M., Jaattela, M., 2004. Sensitization to the lysosomal cell death pathway upon immortalization and transformation. Cancer Research 64, 5301-5310.

Feldstein, A.E., Werneburg, N.W., Li, Z., Bronk, S.F., Gores, G.J., 2006. Bax inhibition protects against free fatty acid-induced lysosomal permeabilization. Am J Physiol

Gastrointest Liver Physiol 290, G1339-1346.
Finnemann, S.C., Leung, L.W., Rodriguez-Boulan, E., 2002. The lipofuscin component A2E selectively inhibits phagolysosomal degradation of photoreceptor phospholipid by the

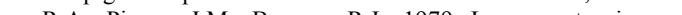

, R.A., Pisano, J.M., Bonney, R.J., 1979. Lysosomotropic agents. 1. Synthesis and Chem $22,1130-1133$

Florey, O., Gammoh, N., Kim, S.E., Jiang, X., Overholtzer, M., 2015. V-ATPase and osmotic imbalances activate endolysosomal LC3 lipidation. Autophagy 11, 88-99.

Foghsgaard, L., Wissing, D., Mauch, D., Lademann, U., Bastholm, L., Boes, M., Elling, F., Leist, M., Jaattela, M., 2001. Cathepsin B acts as a dominant execution protease in tumor cell apoptosis induced by tumor necrosis factor. J Cell Biol 153, 999-1010.

Folick, A., Oakley, H.D., Yu, Y., Armstrong, E.H., Kumari, M., Sanor, L., Moore, D.D., Ortlund, E.A., Zechner. R, Wang, M.C, 2015. Aging Lysosomal signaling molecules regulate longevity in Caenorhabditis elegans. Science 347, 83-86.

Fraldi, A., Annunziata, F., Lombardi, A., Kaiser, H.J., Medina, D.L., Spampanato, C., Fedele, A.O., Polishchuk, R., Sorrentino, N.C., Simons, K., Ballabio, A., 2010. Lysosomal fusion and SNARE function are impaired by cholesterol accumulation in lysosomal storage disorders. Embo J 29, 3607-3620.

Fulda, S., Kogel, D., 2015. Cell death by autophagy: emerging molecular mechanisms and implications for cancer therapy. Oncogene $34,5105-5113$.

Fuster, J.J., Gonzalez, J.M., Edo, M.D., Viana, R., Boya, P., Cervera, J., Verges, M., Rivera, J., Andres, V., 2010. Tumor suppressor p27(Kip1) undergoes endolysosomal degradation through its interaction with sorting nexin 6. Faseb J 24, 2998-3009.

Gabande-Rodriguez, E., Boya, P., Labrador, V., Dotti, C.G., Ledesma, M.D., 2014. High sphingomyelin levels induce lysosomal damage and autophagy dysfunction in Niemann Pick disease type A. Cell Death Differ 21, 864-875.

Galluzzi, L., Aaronson, S.A., Abrams, J., Alnemri, E.S., Andrews, D.W., Baehrecke, E.H., Bazan, N.G., Blagosklonny, M.V., Blomgren, K., Borner, C., Bredesen, D.E., Brenner, C., Castedo, M., Cidlowski, J.A., Ciechanover, A., Cohen, G.M., De Laurenzi, V., De Maria, R., Deshmukh, M., Dynlacht, B.D., El-Deiry, W.S., Favell, R.A., Fulda, S., Hardwick, JM He, Klionsk, D.J., Knight, R. A. Ko. O. Iht, S., Kumar, S., Levine, B, Lipton, S.A. Lugl, Klionsky, D.J., Knight, R.A., Kornbluth, S., Kumar, S., Levine, B., Lipton, S.A., Lugli, Melino, G., Moll, U.M, Morselli, E, Nagata, S., Nicholson, D.W Nicotera, P., Nunez, G., Oren, M. Penninger, J, Pervaiz S. Peter, ME Piacentini, M., Prehn, J.H, Puthalath, H., Rabinovich, G.A., Rizzuto, R. Rodrigues, C.M. Rubingtein, D.C., Rudel, T, Scorrano,
Vandenabeele, P., Vitale, I., Vousden, K.H., Youle, R.J., Yuan, J., Zhivotovsky, B., of assays for monitoring cell death in higher eukaryotes. Cell Death Differ 16, 1093-1107.

Galluzzi, L., Vitale, I., Abrams, J.M., Alnemri, E.S., Baehrecke, E.H., Blagosklonny, M.V., Dawson, T.M., Dawson, V.L., El-Deiry, W.S., Fulda, S., Gottlieb, E., Green, D.R., Hengartner, M.O., Kepp, O., Knight, R.A., Kumar, S., Lipton, S.A., Lu, X., Madeo, F., Malorni, W., Mehlen, P., Nunez, G., Peter, M.E., Piacentini, M., Rubinsztein, D.C., Shi, Y., Simon, H.U., Vandenabeele, P., White, E., Yuan, J., Zhivotovsky, B., Melino, G., Kroemer, G., 2012. Molecular definitions of cell death subroutines: recommendations of the Nomenclature Committee on Cell Death 2012. Cell Death Differ 19, 107-120.

Goetzl, E.J., Boxer, A., Schwartz, J.B., Abner, E.L., Petersen, R.C., Miller, B.L., Kapogiannis, D., 2015. Altered lysosomal proteins in neural-derived plasma exosomes in preclinical Alzheimer disease. Neurology 85, 40-47

Gowrishankar, S., Yuan, P., Wu, Y., Schrag, M., Paradise, S., Grutzendler, J., De Camilli, P., Ferguson, S.M., 2015. Massive accumulation of luminal protease-deficient axonal lysosomes at Alzheimer's disease amyloid plaques. Proc Natl Acad Sci U S A 112,

Groth-Pedersen, L., Jaattela, M., 2013. Combating apoptosis and multidrug resistant cancers by targeting lysosomes. Cancer Lett 332, 265-274.

Guan, J.J, Zhang, X.D. Sun, W., Qi, L., Wu, J.C., Qin, Z.H., 2015. DRAM1 regulates apoptosis through increasing protein levels and lysosomal localization of BAX. Cell Death Dis 6, el624

Guha, S., Coffey, E.E., Lu, W., Lim, J.C., Beckel, J.M., Laties, A.M., Boesze-Battaglia, K., Mitchell, C.H., Liu, J., Baltazar, G., 2014a. Approaches for detecting lysosomal alkalinization and impaired degradation in fresh and cultured RPE cells: evidence for a role in retinal degenerations. Exp Eye Res 126, 68-76.

Guha, S., Liu, J., Baltazar, G., Laties, A.M., Mitchell, C.H., 2014b. Rescue of compromised lysosomes enhances degradation of photoreceptor outer segments and reduces lipofuscin-like autofluorescence in retinal pigmented epithelial cells. Adv Exp Med Biol 801, 105-111.

Gurney, M.E., Pu, H., Chiu, A.Y., Dal Canto, M.C., Polchow, C.Y., Alexander, D.D., Caliendo, J., Hentati, A., Kwon, Y.W., Deng, H.X., et al., 1994. Motor neuron degeneration in mice that express a human $\mathrm{Cu}, \mathrm{Zn}$ superoxide dismutase mutation. Science 264, 17721775 .

Gutierrez, E., Richardson, D.R., Jansson, P.J., 2014. The anticancer agent di-2-pyridylketone 4,4-dimethyl-3-thiosemicarbazone (Dp44mT) overcomes prosurvival autophagy by two mechanisms: persistent induction of autophagosome synthesis and impairment of lysosomal integrity. J Biol Chem 289, 33568-33589.

Hoegen, T., Tremel, N., Klein, M., Angele, B., Wagner, H., Kirschning, C., Pfister, H.W., Fontana, A., Hammerschmidt, S., Koedel, U., 2011. The NLRP3 inflammasome contributes to brain injury in pneumococcal meningitis and is activated through ATPdependent lysosomal cathepsin B release. J Immunol 187, 5440-5451.

Holemans, T., Sorensen, D.M., van Veen, S., Martin, S., Hermans, D., Kemmer, G.C., Van den Haute, C., Baekelandt, V., Gunther Pomorski, T., Agostinis, P., Wuytack, F., Palmgren, M., Eggermont, J., Vangheluwe, P., 2015. A lipid switch unlocks Parkinson's disease-

Hornick, J.R., Vangveravong, S., Spitzer, D., Abate, C., Berardi, F., Goedegebuure, P., Mach, R.H., Hawkins, W.G., 2012. Lysosomal menbrane permeabilization is an early event in Sin 31,41 .

Hu, J.S., Li, Y.B., Wang, J.W., Sun, L., Zhang, G.J., 2007. Mechanism of

lysophosphatidylcholine-induced lysosome destabilization. J Membr Biol $215,27-35$.
A.L., Gottschling, D.E., 2012. An early age increase in vacuolar pH limits mitochondrial function and lifespan in yeast. Nature 492, 261-265. 
Hwang, J.J., Kim, H.N., Kim, J., Cho, D.H., Kim, M.J., Kim, Y.S., Kim, Y., Park, S.J., Koh, J.Y., 2010. Zinc(II) ion mediates tamoxifen-induced autophagy and cell death in MCF-7 breast cancer cell line. Biometals 23, 997-1013.

Isacson, O., 2015. Lysosomes to combat Parkinson's disease. Nat Neurosci 18, 792-793.

Jahn, R., Scheller, R.H., 2006. SNAREs--engines for membrane fusion. Nat Rev Mol Cell Biol 7, 631-643.

Ji, Z.S., Miranda, R.D., Newhouse, Y.M., Weisgraber, K.H., Huang, Y., Mahley, R.W., 2002 Apolipoprotein E4 potentiates amyloid beta peptide-induced lysosomal leakage and apoptosis in neuronal cells. J Biol Chem 277, 21821-21828.

Jouan-Lanhouet, S., Riquet, F., Duprez, L., Vanden Berghe, T., Takahashi, N., Vandenabeele, P., 2014. Necroptosis, in vivo detection in experimental disease models. Semin Cell Dev Biol 35, 2-13

Jung, H., Lee, E.Y., Lee, S.I., 1999. Age-related changes in ultrastructural features of cathepsin B- and D-containing neurons in rat cerebral cortex. Brain Res 844, 43-54.

Kagedal, K., Johansson, A.C., Johansson, U., Heimlich, G., Roberg, K., Wang, N.S., Jurgensmeier, J.M., Ollinger, K., 2005. Lysosomal membrane permeabilization during

Kaur, G., Mohan, P., Pawlik, M., DeRosa, S., Fajiculay, J., Che, S., Grubb, A., Ginsberg, S.D., Nixon, R.A., Levy, E., 2010. Cystatin C rescues degenerating neurons in a cystatin B2267.

Kaushik, S., Massey, A.C., Cuervo, A.M., 2006. Lysosome membrane lipid microdomains:

Kerr, J.F.R., Wyllie, A.H., Currie, A.R., 1972. Apoptosis - Basic Biological Phenomenon with Wide-Ranging Implications in Tissue Kinetics. British Journal of Cancer 26, 239-257.

Kiffin, R., Kaushik, S., Zeng, M., Bandyopadhyay, U., Zhang, C., Massey, A.C., MartinezVicente, M., Cuervo, A.M., 2007. Altered dynamics of the 1 s
chaperone-mediated autophagy with age. J Cell Sci 120, 782-791.

Kikuchi, H., Yamada, T., Furuya, H., Doh-ura, K., Ohyagi, Y., Iwaki, T., Kira, J., 2003. Involvement of cathepsin $\mathrm{B}$ in the motor neuron degeneration of amyotrophic lateral sclerosis. Acta Neuropathol 105, 462-468.

Kirkegaard, T., Jaattela, M., 2009. Lysosomal involvement in cell death and cancer. Biochim Biophys Acta 1793, 746-754.

Kirkegaard, T., Roth, A.G., Petersen, N.H., Mahalka, A.K., Olsen, O.D., Moilanen, I., Zylicz, A., Knudsen, J., Sandhoff, K., Arenz, C., Kinnunen, P.K., Nylandsted, J., Jaattela, M., 2010. Hsp70 stabilizes lysosomes and reverts Niemann-Pick disease-associated lysosomal pathology. Nature 463, 549-553.

Koga, H., Kaushik, S., Cuervo, A.M., 2010. Altered lipid content inhibits autophagic vesicular fusion. FASEB J 24, 3052-3065

Kreuzaler, P.A., Staniszewska, A.D., Li, W., Omidvar, N., Kedjouar, B., Turkson, J., Poli, V., Flavell, R.A., Clarkson, R.W., Watson, C.J., 2011. Stat3 controls lysosomal-mediated cell death in vivo. Nat Cell Biol 13, 303-309.

Kroemer, G., 2015. Autophagy: a druggable process that is deregulated in aging and human disease. J Clin Invest 125, 1-4.

Kroemer, G., Levine, B., 2008. Autophagic cell death: the story of a misnomer. Nat Rev Mol Cell Biol 9, 1004-1010

Kurz, D.J., Decary, S., Hong, Y., Erusalimsky, J.D., 2000. Senescence-associated (beta)galactosidase reflects an increase in lysosomal mass during replicative ageing of human

Laforge, M., Limou, S., Harper, F., Casartelli, N., Rodrigues, V., Silvestre, R., Haloui, H., Zagury, J.F., Se, H. A., Estaquin, J, 2013. DRAM e1003328. Laguna, A., Schintu, N., Nobre, A., Alvarsson, A., Volakakis, N., Jacobsen, J.K., Gomez-Galan,
M., Sopova, E., Joodmardi, E., Yoshitake, T., Deng, Q., Kehr, J., Ericson, J.,
Svenningsson, P., Shupliakov, O., Perlmann, T., 2015. Dopaminergic control of attophagic-lysosomal function implicates Lmxlb in Parkinson's disease. Nat Neurosci $18,826-835$.

Laskar, A., Yuan, X.M., Li, W., 2010. Dimethyl sulfoxide prevents 7beta-hydroxycholesterolinduced apoptosis by preserving lysosomes and mitochondria. J Cardiovasc Pharmacol $56,263-267$

Law, R.H., Zhang, Q., McGowan, S., Buckle, A.M., Silverman, G.A., Wong, W., Rosado, C.J., Langendorf, C.G., Pike, R.N., Bird, P.I., Whisstock, J.C., 2006. An overview of the serpin superfamily. Genome Biol 7, 216.

Lee, D.C., Close, F.T., Goodman, C.B., Jackson, I.M., Wight-Mason, C., Wells, L.M., Womble, T.A., Palm, D.E., 2006. Enhanced cystatin C and lysosomal protease expression following 6-hydroxydopamine exposure. Neurotoxicology 27, 260-276.

Lee, D.C., Womble, T.A., Mason, C.W., Jackson, I.M., Lamango, N.S., Severs, W.B., Palm, D.E., 2007. 6-Hydroxydopamine induces cystatin C-mediated cysteine protease suppression and cathepsin D activation. Neurochem Int 50, 607-618.

Lee, J.H., McBrayer, M.K., Wolfe, D.M., Haslett, L.J., Kumar, A., Sato, Y., Lie, P.P., Mohan, P., Coffey, E.E., Kompella, U., Mitchell, C.H., Lloyd-Evans, E., Nixon, R.A., 2015. Presenilin 1 Maintains Lysosomal $\mathrm{Ca}(2+)$ Homeostasis via TRPML1 by Regulating A.

Lee, J.H., Yu, W.H., Kumar, A., Lee, S., Mohan, P.S., Peterhorf, C.M., Wolfe, D.M., MartinezNicent, M., Massey, A.C., Sovak, G., Pchly Pet, Y., Westaway, D., Cuervo, A.M.,

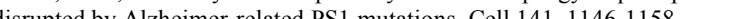

Lin, Y., Epstein, D.L., Liton, P.B., 2010. Intralysosomal iron induces lysosomal membrane permeabilization and cathepsin D-mediated cell death in trabecular meshwork cells exposed to oxidative stress. Invest Ophthalmol Vis Sci 51, 6483-6495.

Lipinski, M.M., Zheng, B., Lu, T., Yan, Z., Py, B.F., Ng, A., Xavier, R.J., Li, C., Yankner, B.A., Scherzer, C.R., Yuan, J., 2010. Genome-wide analysis reveals mechanisms modulating autophagy in normal brain aging and in Alzheimer's disease. Proc Natl Acad Sci U S A 107, 14164-14169.

Liton, P.B., 2016. The autophagic lysosomal system in outflow pathway physiology and pathophysiology. Exp Eye Res 144, 29-37.

Liton, P.B., Lin, Y., Gonzalez, P., Epstein, D.L., 2009. Potential role of lysosomal dysfunction in the pathogenesis of primary open angle glaucoma. Autophagy 5, 122-124.

Liu, L., Zhang, Z., Xing, D., 2011. Cell death via mitochondrial apoptotic pathway due to activation of Bax by lysosomal photodamage. Free Radic Biol Med 51, 53-68.

Loison, F., Xu, Y., Luo, H.R., 2014a. Proteinase 3 and Serpin B1: a novel pathway in the regulation of caspase-3 activation, neutrophil spontaneous apoptosis, and inflammation. Inflamm Cell Signal 1, e462.

Loison, F., Zhu, H., Karatepe, K., Kasorn, A., Liu, P., Ye, K., Zhou, J., Cao, S., Gong, H., Jenne, D.E., Remold-O'Donnell, E., Xu, Y., Luo, H.R., 2014b. Proteinase 3-dependent caspase-3 cleavage modulates neutrophil death and inflammation. J Clin Invest 124, $4445-4458$

Luke, C.J., Pak, S.C., Askew, Y.S., Naviglia, T.L., Askew, D.J., Nobar, S.M., Vetica, A.C., Long, O.S., Watkins, S.C., Stolz, D.B., Barstead, R.J., Moulder, G.L., Bromme, D., Silverman, G.A., 2007. An intracellular serpin regulates necrosis by inhibiting the

Lynch, G., Bi, X., 2003. Lysosomes and brain aging in mammals. Neurochem Res 28, 1725 1734

Mahon, G.J., Anderson, H.R., Gardiner, T.A., McFarlane, S., Archer, D.B., Stitt, A.W., 2004. Chloroquine causes lysosomal dysfunction in neural retina and RPE: implications for retinopathy. Curr Eye Res 28, 277-284

Mantovani, A., Cassatella, M.A., Costantini, C., Jaillon, S., 2011. Neutrophils in the activation and regulation of innate and adaptive immunity. Nat Rev Immunol 11, 519-531. 
Marino, J., Garcia Vior, M.C., Furmento, V.A., Blank, V.C., Awruch, J., Roguin, L.P., 2013. Lysosomal and mitochondrial permeabilization mediates zinc(II) cationic phthalocyanine phototoxicity. Int J Biochem Cell Biol 45, 2553-2562.

Martinez-Vargas, M., Soto-Nunez, M., Tabla-Ramon, E., Solis, B., Gonzalez-Rivera, R., PerezArredondo, A., Estrada-Rojo, F., Castell, A., Molina-Guarneros, J., Navarro, L., 2014. Cystatin C has a dual role in post-traumatic brain injury recovery. Int J Mol Sci 15, 5807-5820.

Masiero, E., Agatea, L., Mammucari, C., Blaauw, B., Loro, E., Komatsu, M., Metzger, D., Reggiani, C., Schiaffino, S., Sandri, M., 2009. Autophagy is required to maintain muscle mass. Cell Metab 10, 507-515.

Matsuda, S., Okada, N., Kodama, T., Honda, T., Iida, T., 2012. A cytotoxic type III secretion effector of Vibrio parahaemolyticus targets vacuolar H+-ATPase subunit $\mathrm{c}$ and ruptures host cell lysosomes. PLoS Pathog 8, e1002803,

Mazzulli, J.R., Xu, Y.H., Sun, Y., Knight, A.L., McLean, P.J., Caldwell, G.A., Sidransky, E., Grabowski, G.A., Krainc, D., 2011. Gaucher disease glucocerebrosidase and alphasynuclein form a bidirectional pathogenic loop in synucleinopathies. Cell 146, 37-52.

McGlinchey, R.P., Lee, J.C., 2015. Cysteine cathepsins are essential in lysosomal degradation of alpha-synuclein. Proc Natl Acad Sci U S A 112, 9322-9327.

Medina, D.L., Di Paola, S., Peluso, I., Armani, A., De Stefani, D., Venditti, R., Montefusco, S., Scotto-Rosato, A., Prezioso, C., Forrester, A., Settembre, C., Wang, W., Gao, Q., Xu, signalling regulates aut 299 .
signaling regulates autophagy through calcineurn and H. EB. Nat Cell Biol 17, 288-

Mena, S., Rodriguez, M.L., Ponsoda, X., Estrela, J.M., Jaattela, M., Ortega, A.L., 2012. Pterostilbene-induced tumor cytotoxicity: a lysosomal membrane permeabilizationPerostilbene-induced tumor cytotoxicity:
dependent mechanism. PloS one 7, e44524.

Mindell, J.A., 2012. Lysosomal acidification mechanisms. Annu Rev Physiol 74, 69-86.

Munson, M.J., Allen, G.F., Toth, R., Campbell, D.G., Lucocq, J.M., Ganley, I.G., 2015. mTOR activates the VPS34-UVRAG complex to regulate autolysosomal tubulation and cell survival. Embo J 34, 2272-2290.

Nakanishi, H., 2003. Neuronal and microglial cathepsins in aging and age-related diseases. Ageing Res Rev 2, 367-381.

Nakanishi, H., Tominaga, K., Amano, T., Hirotsu, I., Inoue, T., Yamamoto, K., 1994. Agerelated changes in activities and localizations of cathepsins D, E, B, and L in the rat brain tissues. Exp Neurol 126, 119-128.

Newton, K., 2015. RIPK1 and RIPK3: critical regulators of inflammation and cell death. Trends Cell Biol 25, 347-353.

Nixon, R.A., 2013. The role of autophagy in neurodegenerative disease. Nat Med 19, 983-997.

Nixon, R.A., Yang, D.S., 2011. Autophagy failure in Alzheimer's disease-locating the primary defect. Neurobiol Dis $43,38-45$.

Norberg, E., Orrenius, S., Zhivotovsky, B., 2010. Mitochondrial regulation of cell death: processing of apoptosis-inducing factor (AIF). Biochem Biophys Res Commun 396, 95 100.

Nylandsted, J., Gyrd-Hansen, M., Danielewicz, A., Fehrenbacher, N., Lademann, U., HoyerHansen, M., Weber, E., Multhoff, G., Rohde, M., Jaattela, M., 2004. Heat shock protein 70 promotes cell survival by inhibiting lysosomal membrane permeabilization. J Exp

Offen, D.,Barhum, Y., Melamed, E., Embacher, N., Schindler, C., Ransmayr, G., 2009. Spinal cord mRNA profile in patients with ALS: comparison with transgenic mice expressing , K., Hir., S. Antant. J Mol Neurosci 38, 85-93.

Okamoto, K. Hirai, S., Amari, M., Watanabe, M., Sakurai, A., 1993. Bunina bodies in amyotrophic lateral sclerosis immunostained with rabbit anti-cystatin $\mathrm{C}$ serum. Neurosci Lett 162, 125-128.
Ono, K., Kim, S.O., Han, J., 2003. Susceptibility of lysosomes to rupture is a determinant for plasma memoris factor alpha-induced cell death. Mol Cell Biol 23, 665-676.

Perez-Sala, D., Boya, P., Ramos, I., Herrera, M., Stamatakis, K., 2009. The C-terminal PLos One 4 , e8117.

Perisic Nanut, M., Sabotic, J., Jewett, A., Kos, J., 2014. Cysteine cathepsins as regulators of the cytotoxicity of NK and T cells. Front Immunol 5, 616

Persson, H.L., Vainikka, L.K., Sege, M., Wennerstrom, U., Dam-Larsen, S., Persson, J., 2012. Leaky lysosomes in lung transplant macrophages: azithromycin prevents oxidative damage. Respir Res 13, 83

Petersen, N.H., Kirkegaard, T., Olsen, O.D., Jaattela, M., 2010. Connecting Hsp70, sphingolipid metabolism and lysosomal stability. Cell Cycle 9, 2305-2309.

Petersen, N.H. Ol Ostenfeld, M.S. Ulanet, D., Dovmark, T. H. Lonborg, A., Vindelov, S.D., Hanahan, D., Arenz, C., Ejsing, C.S., Kirkegaard, T., Rohde, M., Nylandsted, J., Jaattela, M., 2013. Transformation-associated changes in sphingolipid metabolism sensitize cells to lysosomal cell death induced by inhibitors of acid sphingomyelinase. Cancer Cell 24,

Pislar, A.H., Zidar, N., Kikelj, D., Kos, J., 2014. Cathepsin X promotes 6-hydroxydopamine-

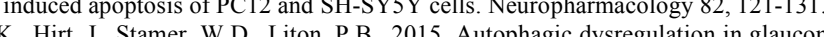

Porter, K., Hirt, J., Stamer, W.D., Liton, P.B., 2015. Autophagic dysregulation in glaucomatous trabecular meshwork cells. Biochim Biophys Acta 1852, 379-385.

Prince, L.R., Bianchi, S.M., Vaughan, K.M., Bewley, M.A., Marriott, H.M., Walmsley, S.R., Taylor, G.W., Buttle, D.J., Sabroe, I., Dockrell, D.H., Whyte, M.K., 2008. Subversion of a lysosomal pathway regulating neutrophil apoptosis by a major bacterial toxin, pyocyanin. J Immunol 180, 3502-3511.

Qiao, L., Hamamichi, S., Caldwell, K.A., Caldwell, G.A., Yacoubian, T.A., Wilson, S., Xie, Z.L., Speake, L.D., Parks, R., Crabtree, D., Liang, Q., Crimmins, S., Schneider, L.,
Uchiyama, Y., Iwatsubo, T., Zhou, Y., Peng, L., Lu, Y., Standaert, D.G., Walls, K.C., Shacka, J.J., Roth, K.A., Zhang, J, 2008. Lysosomal enzyme cathepsin D protects against alpha-synuclein aggregation and toxicity. Mol Brain 1,17 .

Reeg, S., Grune, T., 2015. Protein Oxidation in Aging: Does It Play a Role in Aging Progression? Antioxid Redox Signal 23, 239-255.

Rocha, E.M., Smith, G.A., Park, E., Cao, H., Brown, E., Hallett, P., Isacson, O., 2015. Progressive decline of glucocerebrosidase in aging and Parkinson's disease. Ann Clin Transl Neurol 2, 433-438.

Rodriguez-Muela, N., Hernandez-Pinto, A.M., Serrano-Puebla, A., Garcia-Ledo, L., Latorre, S.H., de la Rosa, E.J., Boya, P., 2015. Lysosomal membrane permeabilization and autophagy blockade contribute to photoreceptor cell death in a mouse model of retinitis pigmentosa. Cell Death Differ 22, 476-487.

Rodriguez-Muela, N. Koga, H., Garcia-Ledo, L., de la Villa, P de la Rosa, E J Cuervo, A.M., Boya, P., 2013. Balance between autophagic pathways preserves retinal homeostasis. Aging Cell 12, 478-488.

Rodriguez-Navarro, J.A., Kaushik, S., Koga, H., Dall'Armi, C., Shui, G., Wenk, M.R., Di Paolo, G., Cuervo, A.M., 2012. Inhibitory effect of dietary lipids on chaperone-mediated autophagy. Proc Natl Acad Sci U S A 109, E705-714

Roussi, S., Gosse, F., Aoude-Werner, D., Zhang, X., Marchioni, E., Geoffroy, P., Miesch, M., perturbation, oxidative stress and lysosomal destabilization are involved in 7beta-hydroxysitosterol and 7beta-hydroxycholesterol triggered apoptosis in human colon cancer cells. Apoptosis 12, 87-96.

Saftig, P., Klumperman, J., 2009. Lysosome biogenesis and lysosomal membrane proteins: trafficking meets function. Nat Rev Mol Cell Biol 10, 623-635. 
Sancho-Pelluz, J., Arango-Gonzalez, B., Kustermann, S., Romero, F.J., van Veen, T., Zrenner, E. Ekstrom, P. Paquet-Durand, F, 2008. Photoreceptor cell death mechanisms in inherited retinal degeneration. Mol Neurobiol 38, 253-269.

Sardiello, M., Palmieri, M., di Ronza, A., Medina, D.L., Valenza, M., Gennarino, V.A., Di Malta, C., Donaudy, F., Embrione, V., Polishchuk, R.S., Banfi, S., Parenti, G., Cattaneo, E., Ballabio, A., 2009. A gene network regulating lysosomal biogenesis and function. Science $325,473-477$.

Sargeant, T.J., Lloyd-Lewis, B., Resemann, H.K., Ramos-Montoya, A., Skepper, J., Watson, C.J., 2014. Stat3 controls cell death during mammary gland involution by regulating uptake of milk fat globules and lysosomal membrane permeabilization. Nat Cell Biol $16,1057-1068$

Schweichel, J.U., Merker, H.J., 1973. The morphology of various types of cell death in prenatal tissues. Teratology 7, 253-266.

Serrano-Puebla, A., Boya, P., 2015. Lysosomal membrane permeabilization in cell death: new evidence and implications for health and disease. Ann N Y Acad Sci.

Settembre, C., Ballabio, A., 2014. Lysosome: regulator of lipid degradation pathways. Trends Cell Biol 24, 743-750.

Settembre, C., Fraldi, A., Medina, D.L., Ballabio, A., 2013. Signals from the lysosome: a control centre for cellular clearance and energy metabolism. Nat Rev Mol Cell Biol 14

Sevlever D., Jiang, P., Yen, S.H., 2008. Cathepsin D is the main lysosomal enzyme involved in the degradation of alpha-synuclein and generation of its carboxy-terminally truncated species. Biochemistry 47, 9678-9687.

Shen, D., Wang, X., Li, X., Zhang, X., Yao, Z., Dibble, S., Dong, X.P., Yu, T., Lieberman, 列 731.

Shen, H.M., Mizushima, N., 2014. At the end of the autophagic road: an emerging understanding of lysosomal functions in autophagy. Trends Biochem Sci 39, 61-71.

Stefani, C., Al-Eisawi, Z., Jansson, P.J., Kalinowski, D.S., Richardson, D.R., 2015. Identification of differential anti-neoplastic activity of copper bis(thiosemicarbazones) that is mediated by intracellular reactive oxygen specie
membrane permeabilization. J Inorg Biochem 152, 20-37.

Subrizi, A., Toropainen, E., Ramsay, E., Airaksinen, A.J., Kaarniranta, K., Urtti, A., 2015. Oxidative stress protection by exogenous delivery of rhHsp70 chaperone to the retinal pigment epithelium (RPE), a possible therapeutic strategy against RPE degeneration. Pharm Res 32, 211-221.

Taha, T.A., Kitatani, K., Bielawski, J., Cho, W., Hannun, Y.A., Obeid, L.M., 2005. Tumor necrosis factor induces the loss of sphingosine kinase-1 by a cathepsin B-dependent mechanism. J Biol Chem 280, 17196-17202.

Taniguchi, M., Ogiso, H., Takeuchi, T., Kitatani, K., Umehara, H., Okazaki, T., 2015. Lysosomal ceramide generated by acid sphingomyelinase triggers cytosolic cathepsin B-mediated degradation of X-linked inhibitor of apoptosis protein in natural killer/T lymphoma cell apoptosis. Cell Death Dis 6, e1717

Terman, A., 1995. The effect of age on formation and elimination of autophagic vacuoles in mouse hepatocytes. Gerontology 41 Suppl 2, 319-326.

Terman, A., Kurz, T., Gustafsson, B., Brunk, U.T., 2006. Lysosomal labilization. IUBMB Life

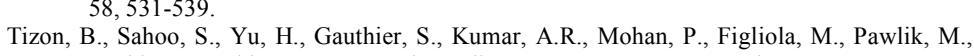
Grubb, A., Uchiyama, Y., Bandyopadhyay, U., Cuervo, A.M., Nixon, R.A., Levy, E., 2010. Induction of autophagy by cystatin C: a mechanism that protects murine primary

Tramutola, A., Triplett, J.C., Di Domenico, F., Niedowicz, D.M., Murphy, M.P., Coccia, R., Perluigi, M., Butterfield, D.A., 2015. Alteration of mTOR signaling occurs early in the progression of Alzheimer disease $(\mathrm{AD})$ : analysis of brain from subjects with pre-clinical
AD, amnestic mild cognitive impairment and late-stage AD. J Neurochem 133, 739-

Trincheri, NF. Nicotra, G., Follo, C., Castino, R., Isidoro, C., 2007. Resveratrol induces cell death in colorectal cancer cells by a novel pathway involving lysosomal cathepsin D. Carcinogenesis 28, 922-931.

Tseng, W.A., Thein, T., Kinnunen, K., Lashkari, K., Gregory, M.S., D'Amore, P.A., Ksander, B.R., 2013. NLRP3 inflammasome activation in retinal pigment epithelial cells by lysosomal destabilization: implications for age-related macular degeneration. Invest Ophthalmol Vis Sci 54, 110-120

Tsuji-Akimoto, S., Yabe, I., Niino, M., Kikuchi, S., Sasaki, H., 2009. Cystatin C in cerebrospinal fluid as a biomarker of ALS. Neurosci Lett 452, 52-55.

Turk, V., Bode, W., 1991. The cystatins: protein inhibitors of cysteine proteinases. FEBS Lett 285, 213-219.

Turk, V., Turk, B., Turk, D., 2001. Lysosomal cysteine proteases: facts and opportunities. Embo J 20, 4629-4633.

Ullio, C., Casas, J., Brunk, U.T., Sala, G., Fabrias, G., Ghidoni, R., Bonelli, G., Baccino, F.M., Autelli, R., 2012. Sphingosine mediates TNFalpha-induced lysosomal membrane permeabilization and ensuing programmed cell death in hepatoma cells. J Lipid Res 53,

Ullman, E., Pan, J.A., Zong, W.X., 2011. Squamous cell carcinoma antigen 1 promotes caspase8-mediated apoptosis in response to endoplasmic reticulum stress while inhibiting

Varga, R.E., Khundadze, M., Damme, M., Nietzsche, S., Hoffmann, B., Stauber, T., Koch, N., Hennings, J.C., Franzka, P., Huebner, A.K., Kessels, M.M., Biskup, C., Jentsch, T.J., Qualmann, B., Braulke, T., Kurth, I., Beetz, C., Hubner, C.A., 2015. In Vivo Evidence for Lysosome Depletion and Impaired Autophagic Clearance in Hereditary Spastic Paraplegia Type SPG11. PLoS Genet 11, e1005454.

Vila, M., Bove, J., Dehay, B., Rodriguez-Muela, N., Boya, P., 2011. Lysosomal membrane permeabilization in Parkinson disease. Autophagy 7, 98-100.

Villalpando Rodriguez, G.E., Torriglia, A., 2013. Calpain 1 induce lysosomal permeabilization by cleavage of lysosomal associated membrane protein 2. Biochim Biophys Acta 1833 , 2244-2253.

Vittorini, S., Paradiso, C., Donati, A., Cavallini, G., Masini, M., Gori, Z., Pollera, M., Bergamini, E., 1999. The age-related accumulation of protein carbonyl in rat liver correlates with the age-related decline in liver proteolytic activities. J Gerontol A Biol Sci Med Sci 54, B318-323.

Wang, W., Gao, Q., Yang, M., Zhang, X., Yu, L., Lawas, M., Li, X., Bryant-Genevier, M., Southall, N.T., Marugan, J., Ferrer, M., Xu, H., 2015. Up-regulation of lysosomal TRPML1 channels is essential for lysosomal adaptation to nutrient starvation. Proc Natl Acad Sci U S A 112, E1373-1381.

Wartosch, L., Bright, N.A., Luzio, J.P., 2015. Lysosomes. Curr Biol 25, R315-316.

atanabe, S., Hayakawa, T., Wakasugi, K., Yamanaka, K., 2014. Cystatin C protects neuronal cells against mutant copper-zinc superoxide dismutase-mediated toxicity. Cell Death Dis 5 , el 1497 .

Werneburg, N.W., Bronk, S.F., Guicciardi, M.E., Thomas, L., Dikeakos, J.D., Thomas, G., Gores, G.J., 2012. Tumor necrosis factor-related apoptosis-inducing ligand (TRAIL) protein-induced lysosomal translocation of proapoptotic effectors is mediated by
phosphofurin acidic cluster sorting protein-2 (PACS-2). J Biol Chem 287, 2442724437

Werneburg, N.W., Guicciardi, M.E., Bronk, S.F., Gores, G.J., 2002. Tumor necrosis factoralpha-associated lysosomal permeabilization is cathepsin B dependent. American alpha-associated lysosomal permeabilization is cathepsin B dependent. A
Journal of Physiology-Gastrointestinal and Liver Physiology 283, G947-G956.

Windelborn, J.A., Lipton, P., 2008. Lysosomal release of cathepsins causes ischemic damage in the rat hippocamel slice and depends on NMDA-mediated calcium influx, arachidonic acid metabolism, and free radical production. J Neurochem 106, 56-69. 
Wolfe, D.M., Lee, J.H., Kumar, A., Lee, S., Orenstein, S.J., Nixon, R.A., 2013. Autophagy failure in Alzheimer's disease and the role of defective lysosomal acidification. Eur Neurosci 37, 1949-1961.

Wootz, H., Weber, E., Korhonen, L., Lindholm, D., 2006. Altered distribution and levels of cathepsinD and cystatins in amyotrophic lateral sclerosis transgenic mice: possible roles in motor neuron survival. Neuroscience 143, 419-430.

Xiang, Y., Yan, C., Guo, X., Zhou, K., Li, S., Gao, Q., Wang, X., Zhao, F., Liu, J., Lee, W.H., Zhang, Y., Kennedy, C.L., Smith, D.J., Lyras, D., Chakravorty, A., Rood, J.I., 2014. Host-derived, pore-forming toxin-like protein and trefoil factor complex protects the host against microbial infection. Proc Natl Acad Sci U S A 111, 6702-6707.

Xu, H., Ren, D., 2015. Lysosomal physiology. Annu Rev Physiol 77, 57-80.

Yamashima, T., 2013. Reconsider Alzheimer's disease by the 'calpain-cathepsin hypothesis'--a perspective review. Prog Neurobiol 105, 1-23.

Yamashima, T., Oikawa, S., 2009. The role of lysosomal rupture in neuronal death. Prog Neurobiol 89, 343-358.

Yang, A.J., Chandswangbhuvana, D., Margol, L., Glabe, C.G., 1998. Loss of endosomal//ysosomal membrane impermeability is an early event in amyloid Abeta1-42

pathogenesis. J Neurosci Res 52, 691-698.
Yang, D.S., Stavrides, P., Saito, M., Kumar, A., Rodriguez-Navarro, J.A., Pawlik, M., Huo, C., Walkley, S.U., Cuervo, A.M., Nixon, R.A., 2014. Defective macroautophagic turnover lysosomal proteolytic deficits. Brain 137, 3300-3318.

, Whe, Wan, Termination of autophagy and reformation of lysosomes regulated by mTOR., Nature 465, 942-946.

Zang, Y., Beard, R.L., Chandraratna, R.A., Kang, J.X., 2001. Evidence of a lysosomal pathway for apoptosis induced by the synthetic retinoid CD437 in human leukemia HL-60 cells. Cell Death Differ 8, 477-485.

Zhang, C., Cuervo, A.M., 2008. Restoration of chaperone-mediated autophagy in aging liver improves cellular maintenance and hepatic function. Nat Med 14, 959-965.

Zhang, G., Yi, Y.P., Zhang, G.J., 2006. Effects of arachidonic acid on the lysosomal ion permeability and osmotic stability. J Bioenerg Biomembr 38, 75-82.

Zhang, H., Baehrecke, E.H., 2015. Eaten alive: novel insights into autophagy from multicellular model systems. Trends Cell Biol 25, 376-387.

Zhang, Y., Yang, N.D., Zhou, F., Shen, T., Duan, T., Zhou, J., Shi, Y., Zhu, X.Q., Shen, H.M., 2012. (-)-Epigallocatechin-3-gallate induces non-apoptotic cell death in human cancer cells via ROS-mediated lysosomal membrane permeabilization. PloS one 7, e46749.

Zhu, W., Tao, L., Quick, M.L., Joyce, J.A., Qu, J.M., Luo, Z.Q., 2015. Sensing cytosolic RpsL by macrophages induces lysosomal cell death and termination of bacterial infection. PLoS Pathog 11, e1004704. 


\section{Extrinsic}

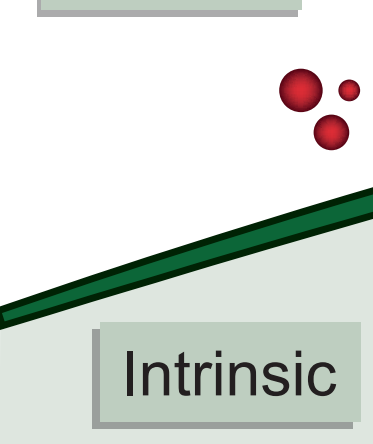

Triggers

Executors

Caspase inhibitors

Bcl-2 overexpression Antioxidants

Cathepsins

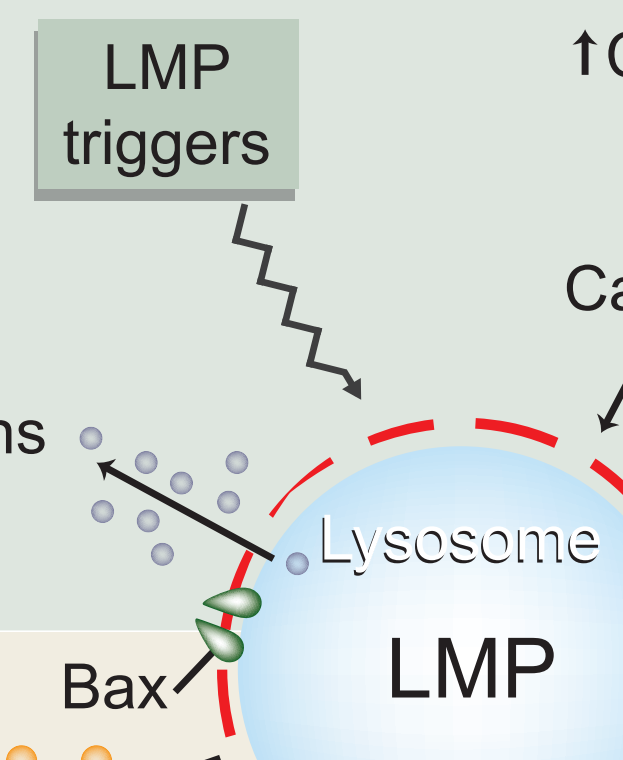

$\uparrow \mathrm{Ca}^{2+}$ i1

1

Integrators

MMP Bax IVIM

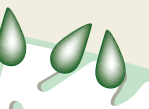

Inhibitors

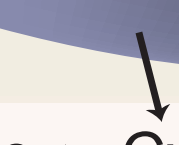

Apoptosome $\leftarrow$ Cyt c<smiles>C[13CH2][13CH2][13CH2]</smiles>
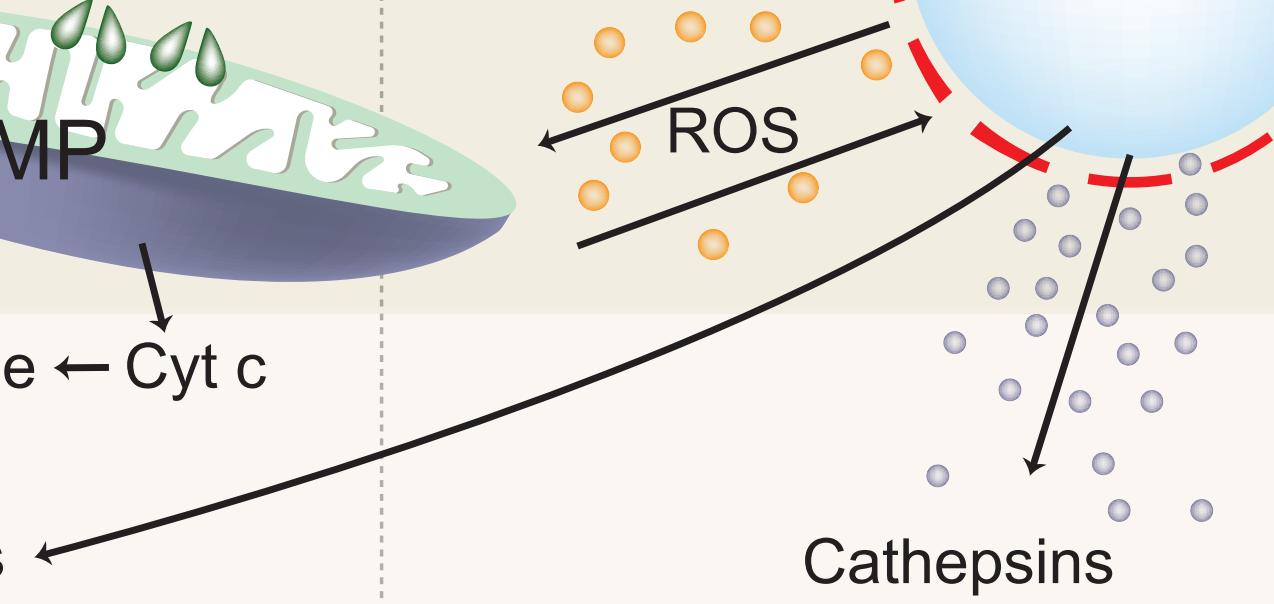

Cathepsin inhibitors

Serpins, Cystatins, Antioxidants, Ion Chelators

Necrostatin 

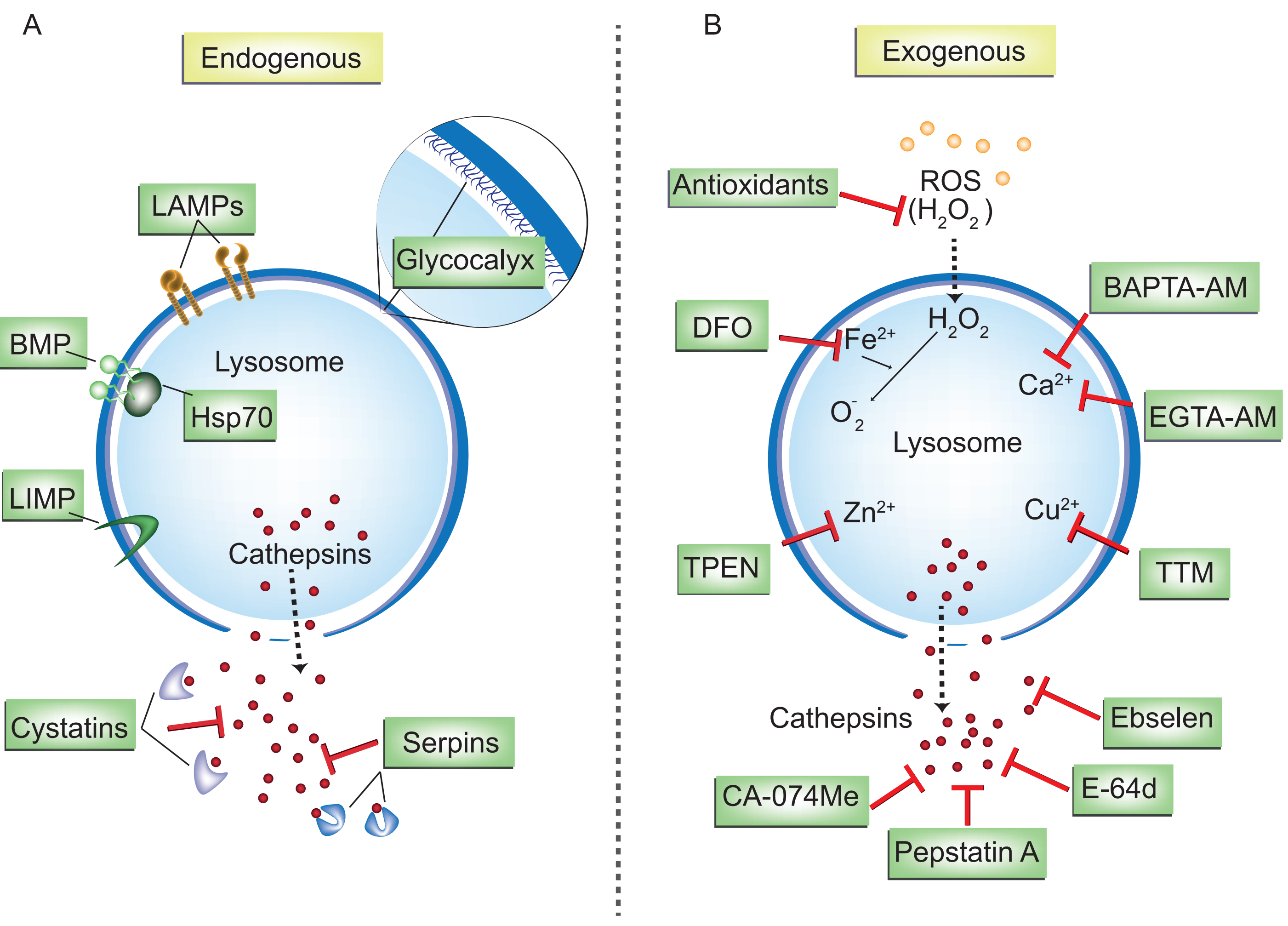


\section{Mature lysosome}
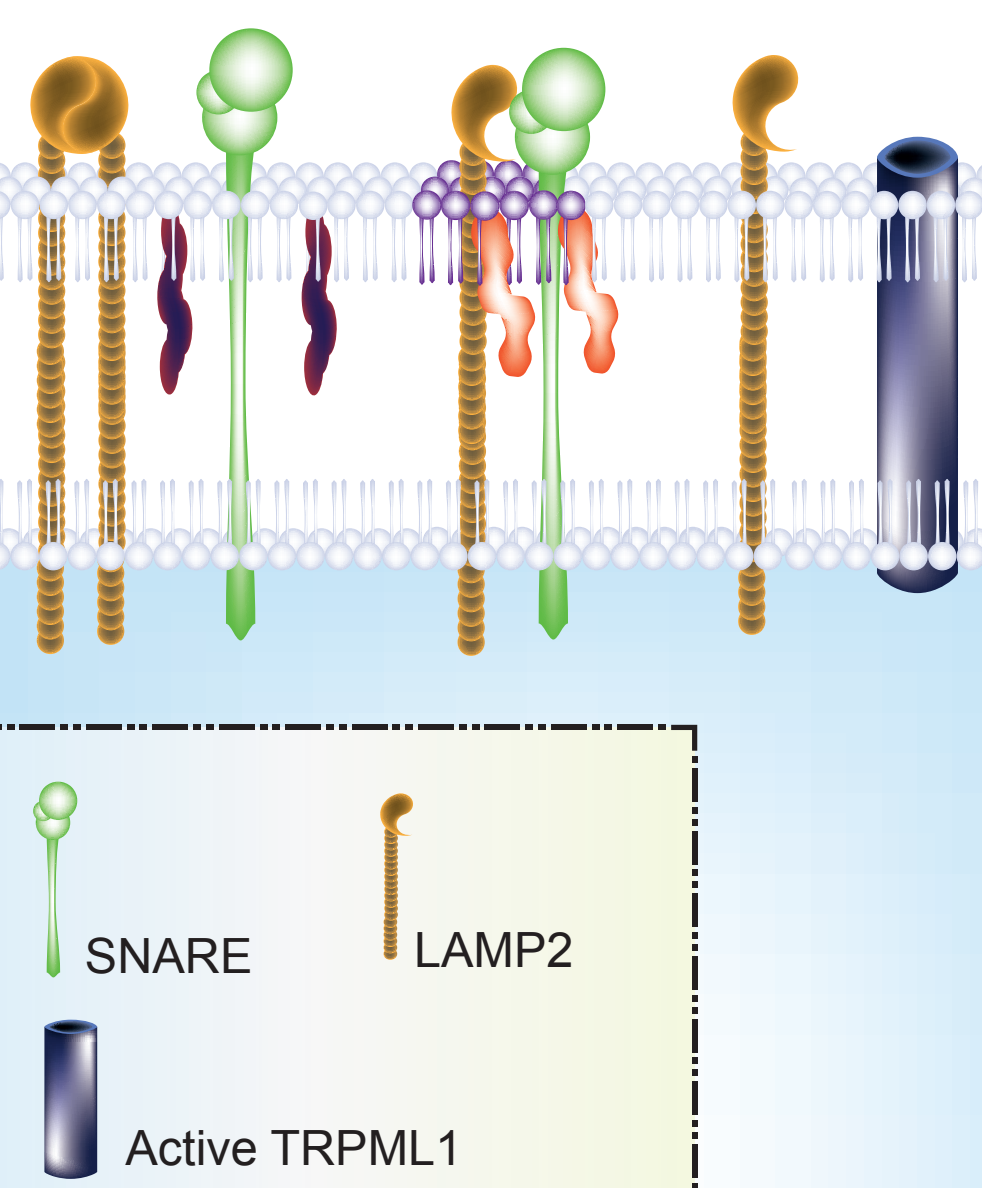

PSphingomyelin SCholesterol

Lysophosphatidylcholine

Cytoplasm

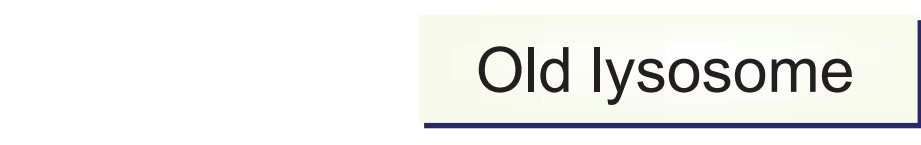

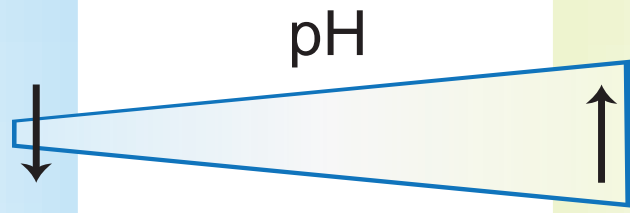

Cathepsin activity

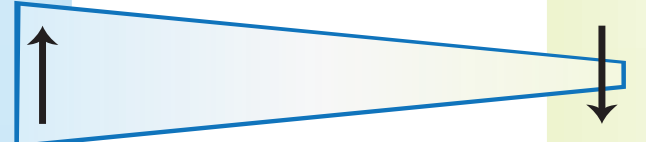

Substrate availability

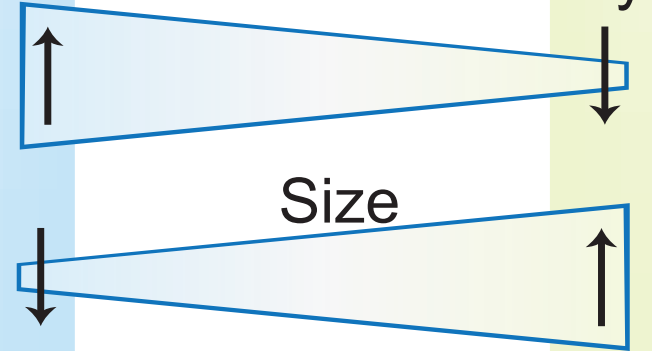

11

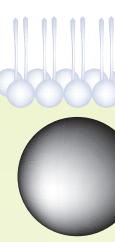

O

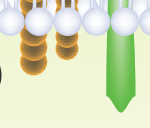

Lipofuscin

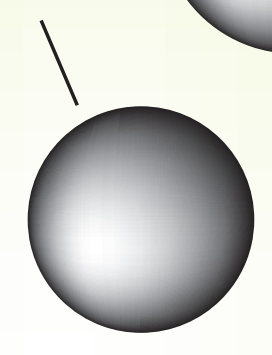

O

o Short saturated sphingomyelin

Less active TRPML1 